\title{
Extreme flood response to short-duration convective rainfall in South-West Germany
}

\author{
V. Ruiz-Villanueva ${ }^{1}$, M. Borga ${ }^{2}$, D. Zoccatelli ${ }^{2}$, L. Marchi ${ }^{3}$, E. Gaume ${ }^{4}$, and U. Ehret ${ }^{5}$ \\ ${ }^{1}$ Department of Research and Geoscientific Prospective, Geological Survey of Spain (IGME), Madrid, Spain \\ ${ }^{2}$ Dipartimento Territorio e Sistemi Agro-Forestali, Università di Padova, Legnaro, Italy \\ ${ }^{3}$ CNR IRPI, Padova, Italy \\ ${ }^{4}$ LUNAM Université, IFSTTAR, GER, 44341 Bouguenais, France \\ ${ }^{5}$ Institut für Wasser und Gewässerentwicklung, Bereich Hydrologie KIT, Karlsruhe, Germany
}

Correspondence to: V. Ruiz-Villanueva (v.ruiz@igme.es)

Received: 22 November 2011 - Published in Hydrol. Earth Syst. Sci. Discuss.: 7 December 2011

Revised: 22 April 2012 - Accepted: 28 April 2012 - Published: 31 May 2012

\begin{abstract}
The 2 June 2008 flood-producing storm on the Starzel river basin in South-West Germany is examined as a prototype for organized convective systems that dominate the upper tail of the precipitation frequency distribution and are likely responsible for the flash flood peaks in Central Europe. The availability of high-resolution rainfall estimates from radar observations and a rain gauge network, together with indirect peak discharge estimates from a detailed post-event survey, provided the opportunity to study in detail the hydrometeorological and hydrological mechanisms associated with this extreme storm and the ensuing flood. Radar-derived rainfall, streamgauge data and indirect estimates of peak discharges are used along with a distributed hydrologic model to reconstruct hydrographs at multiple locations. Observations and model results are combined to examine two main questions, (i) assessment of the distribution of the runoff ratio for the 2008 flash flood and how it compares with other less severe floods; and (ii) analysis of how the spatial and temporal distribution of the extreme rainfall, and more specifically storm motion, controls the flood response. It is shown that small runoff ratios (less than $20 \%$ ) characterized the runoff response and that these values are in the range of other, less extreme, flood events. The influence of storm structure, evolution and motion on the modeled flood hydrograph is examined by using the "spatial moments of catchment rainfall". It is shown that downbasin storm motion (in the range of $0.7-0.9 \mathrm{~m} \mathrm{~s}^{-1}$ ) had a noticeable impact on flood response by increasing the modeled flood peak by $13 \%$.
\end{abstract}

\section{Introduction}

Analyses of inventories of flash floods in Europe have outlined seasonality effects and associated space-time scales in the distribution of these events across different European regions (Gaume et al., 2009; Marchi et al., 2010). According to these analyses, major flash floods in the Mediterranean region (Italy, France and Catalonia) mostly occur in the autumn months, whereas events in the inland Continental region (Romania, Slovakia, Austria and Germany) tend to occur in the summer months, revealing different climatic forcing. Consistent with the seasonality effect, these analyses have shown that the spatial extent and duration of the events is smaller for the Continental events compared to those occurring in the Mediterranean region. Even though the flash flood regime is generally more intense in the Mediterranean Region than in the Continental areas, flash floods occurring in the belt from Southern Germany to Romania play a specific role in the regional flood hydrology at small drainage areas (less than $100 \mathrm{~km}^{2}$ ). Organized convective systems dominate the upper tail of the precipitation frequency distributions for short duration rainfall and are likely responsible for the flood peaks at small drainage areas in this region (Parajka et al., 2010). Past studies have reported indications that flash floods in this region are characterized by relatively low values of runoff ratio, defined as the portion of rainfall that becomes direct runoff during a flood (Marchi et al., 2010). An important implication of these indications is that flash flood forecasting in this region may be inherently more uncertain than in 
other European regions (Borga et al., 2011). The flash flood generating-storm events are shorter, which imply that flood forecasting relies largely on precipitation nowcasting. Moreover, if one views runoff as the difference between two uncertain values of similar magnitude, it is not surprising that runoff is poorly forecasted.

Flash floods are spatially-limited, locally rare events whose observation and monitoring is challenging given the available hydro-meteorological networks (Carpenter et al., 2007; Borga et al., 2008; Brauer et al., 2011). The recognition of the poor observability of flash floods has stimulated in the last decade the development of a focused monitoring methodology, which involves post-flood surveys, use of weather radar observations and hydrological modelling (Costa and Jarrett, 2008; Borga et al., 2008; Gaume and Borga, 2008; Brauer et al., 2011). The implementation of this observation strategy has led to an improved characterisation of flash floods, both at the individual event scale (Hicks et al., 2005; Delrieu et al., 2005) and at the regional, multi-event scale (Costa and Jarrett, 2008; Gaume et al., 2009). Statistical regional procedures have been developed which may explicitly incorporate data from post-flood surveys to improve the estimation of extreme quantiles (Gaume et al., 2010). Ongoing research focuses on understanding how the data generated by this observational methodology may be used to discriminate among various hypotheses of runoff generation under flash flood conditions (Braud et al., 2010; Bonnifait et al., 2009), to test flash flood forecasting models (Norbiato et al., 2008; Versini et al., 2010) and to identify patterns of predictability (Blöschl, 2006).

In this paper, we examine the hydrometeorology and hydrology of an extreme flood in the Starzel catchment at Rangendingen (a $120 \mathrm{~km}^{2}$ sub-basin of the Neckar river system in South-Western Germany, Fig. 1), through analyses of the 2 June 2008 storm and flood. As an "end member" in the flood response spectrum at small drainage areas (Uhlenbrook et al., 2002), analyses of Starzel response provide insights into the processes that produce extreme floods in smallmedium size catchments in South-Western Germany. The 2 June 2008 flood in the Starzel river basin, similar to other extreme floods in the region, was produced by an organized system of thunderstorms. The storm produced large rainfall rates over the Starzel River catchment for a period of approximately $1 \mathrm{~h} 30 \mathrm{~min}$ and claimed the lives of three people. Estimates of the related rainfall event are based on volume scan reflectivity observations from two C-band weather radars operated by the German Weather Service (DWD) (Fig. 1). The rainfall estimates are used to characterize the structure and motion of the flash flood-producing storm and as an input to a distributed hydrological model for flood simulation.

A detailed post-flood survey was carried out in the period 10-14 November 2008 by an international team of experts. The field work included indirect estimation of peak discharges from flood marks (Lumbroso and Gaume, 2011) and documentation of the time evolution of the flood by means of information collected from eyewitnesses of the flood and local authorities. Overall, this has made it possible to depict a spatially-detailed pattern of flash-flood response along the stream network.

Two main questions are examined in this study based on the observational and modeling resources. First, we aim to quantify the distribution of the values of event runoff ratios across the various subbasins surveyed during the postevent survey, and to compare these values with those obtained from the analysis of less severe flood events. Analysis of event runoff ratios may provide essential insight on how the landscape "filter" rainfall to generate runoff and how the observed differences can be explained by the storm characteristics. Moreover, these observations may be used to confirm or reject findings about the distribution of runoff ratios for flash floods in the Central European region. Second, we aim to analyze how the spatial and temporal distribution of the extreme rainfall, and more specifically storm motion, controls flood response. This question has been rarely examined with reference to real flood events, essentially because of lack of a methodology relating the space-time properties of rainfall to the drainage basin properties. There are a number of aspects related to storm movement which have an impact on the flood response. Among these, the direction and the speed of the storm motion with respect to the catchment morphology is probably the most important one (Seo et al., 2012). To examine in a quantitative way these aspects, we use here the concept of "catchment scale storm velocity" proposed by Zoccatelli et al. (2011) and based on the spatial moments of catchment rainfall. These statistics, which build on previous work by Viglione et al. (2010) and correspond in part to the catchment rainfall statistics reported in Smith et al. $(2002,2005)$, assess the dependence of the catchment flood response on the space-time interaction between rainfall and the spatial organization of catchment flow pathways. Whereas the techniques like cross-correlation applied to the radar images time series may be used to identify the overall storm velocity, the catchment-scale storm velocity provides a map of the overall storm velocity over specific catchment configurations. The catchment-scale storm velocity has therefore an implicit hydrological meaning. Zoccatelli et al. (2011) showed that an upbasin (downbasin) velocity is associated to a decrease (increase) of flood peak with respect to an equivalent stationary storm. A finding which is often reported is that the effect of storm motion on flood peak is maximized when storm velocity has similar magnitude as the channel flow velocity (Singh, 1998; Seo et al., 2012). Moreover, we introduce a methodology to evaluate the impact of neglecting the storm velocity in flood modeling. This assessment bears important implications on the storm properties which should be monitored for effective flash flood forecasting and more in general for flood risk management. 


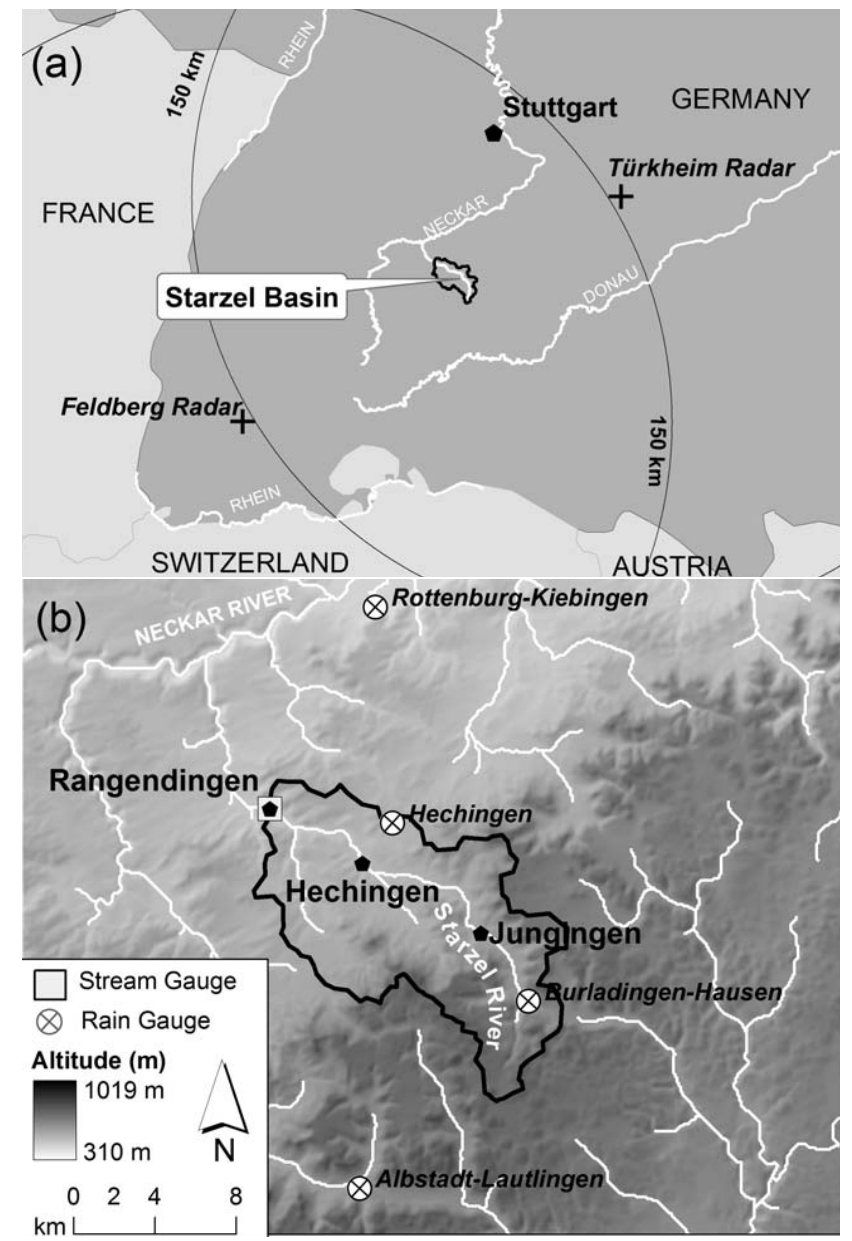

Fig. 1. (a) Location of the Starzel basin with the two weather radars, Türkheim and Feldberg (crosses) and corresponding $150 \mathrm{~km}$ range circles; (b) the basin with orography and the location of the four raingauge stations and of the streamgauge.

\section{The study area and its flood regime}

The catchment of the Starzel river closed at Rangendingen (Fig. 1), which includes the area most severely affected by the flash flood of 2 June 2008 , covers an area of $120 \mathrm{~km}^{2}$. The elevation ranges from 419 to $954 \mathrm{~m}$ a.s.l. (average $644 \mathrm{~m}$ ) and the mean slope is $12 \%$.

The catchment consists mainly of Jurassic sedimentary rocks, predominantly limestone, marls and claystone. Karst topography including fissures, sinkholes and caverns, is locally observed on the very eastern portions of the catchment, where limestone outcrops. Three main land use classes can be found in the catchment (Fig. 2): forest, agriculture and urban areas. Coniferous, mixed and deciduous forests cover most of basin slopes. Agricultural areas mostly consist of arable land, orchards and meadows. The catchment includes three major urban areas: Jungingen (1416 inhabitants), Hechingen (19386 inhabitants) and Rangendingen (5400 inhabitants).

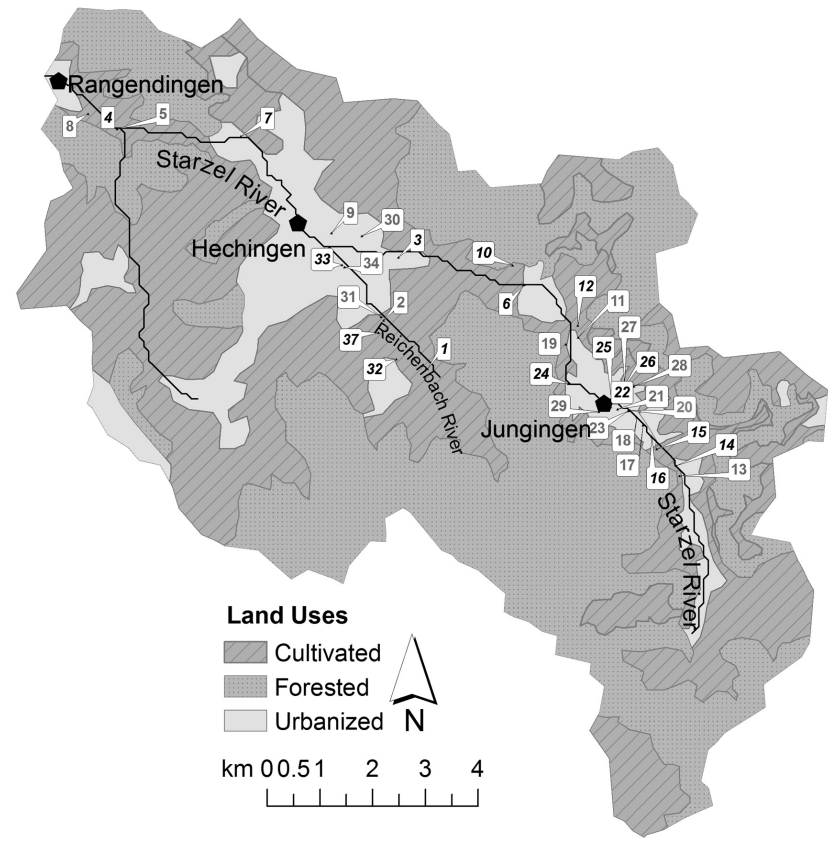

Fig. 2. Land use map of the Starzel catchment. Numbers refer to the surveyed cross sections during the intensive post event campaign; the 17 sections considered for the study are marked in bold.

According to long term data (1961-1990) recorded in Hechingen, average annual precipitation is $836 \mathrm{~mm}$, with maxima in summer (from June to August); mean annual temperature is $8.3^{\circ} \mathrm{C}$, with minimum in January $\left(-0.5^{\circ} \mathrm{C}\right)$ and maximum in July $\left(17.3^{\circ} \mathrm{C}\right)$. The Starzel river catchment is part of the Neckar river system (Fig. 1). As shown by the relief map in Fig. 1b, it is situated at the edge of a Karst plateau named Schwäbische Alb. In the catchments along this edge, runoff production is influenced by karst effects caused by the Schwäbische Alb in the South. Also, the rim of the plateau is a typical spot for the triggering of convective uplift, which facilitates thunderstorm formation. Mean annual rainfall along the rim lies at $900-1000 \mathrm{~mm}$.

Estimates of the 2 June 2008 flood peak at Rangendingen range between 125 and $175 \mathrm{~m}^{3} \mathrm{~s}^{-1}$, with a central value of $150 \mathrm{~m}^{3} \mathrm{~s}^{-1}$. In order to provide a context for the Starzel flash flood, we examined the flood hydrology of the catchments along the Schwäbische Alb rim. The analysis of regional extreme floods is based on data from 15 stream gauges, namely peak discharge of the three highest recorded floods (Fig. 3) and 2-yr and 100-yr peak discharge statistics derived from streamgauge measurements provided by the local water authorities. The catchments considered in the analysis were selected to be similar in size to the Starzel at Rangendingen $\left(120 \mathrm{~km}^{2}\right)$, with areas ranging from 29 to $331 \mathrm{~km}^{2}$. A total of $498 \mathrm{yr}$ of peak flow observations is included in the overall regional sample, with a mean record length of $33 \mathrm{yr}$. The recurrence period of the three highest recorded flood events for each catchment range from 2-yr to $>100$-yr floods (more 


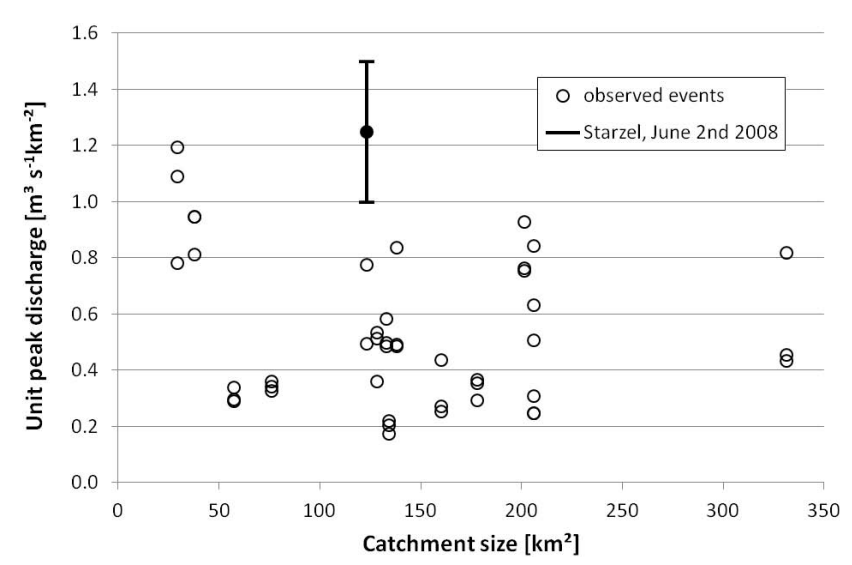

Fig. 3. Unit peak discharges vs. catchment size for the three highest observed flood peaks observed in 15 catchments in the Neckar river system near the Starzel. The uncertainty range corresponding to the Starzel flash flood peak estimated in Rangendingen is also reported.

than $70 \%$ are larger than 10 -yr floods). These data provide a representative sample of extreme floods in the region. The information about the climatology of extreme precipitation is provided in the form of gridded $(8.4 \mathrm{~km})$ rainfall amounts for various durations $(5 \mathrm{~min}-72 \mathrm{~h})$ and return periods derived from raingauge statistics from the KOSTRA project (DWD, 1997).

The three highest recorded flood events at each of the 15 gauges are characterized according to the month of flood occurrence. Almost $75 \%$ of the floods occur in the period MayAugust. The Starzel event of June 2008 is therefore representative in this region with respect to occurrence season. In fact, the three highest recorded floods at gauge Rangendingen, in operation since 1991, all occurred during this season (the other two largest floods occurred on 11 August 2002 and 21 June 2007). From an historical perspective, the largest flood in the region for which information is reported (albeit not in the form of a systematic record) occurred on 47 June 1895 in a catchment close to the Starzel river: the Eyach river basin at Balingen $\left(128 \mathrm{~km}^{2}\right)$. The event consisted of three individual flood events that occurred on 4, 5 and 7 June 1895 each caused by intense thunderstorms totaling around $200 \mathrm{~mm}$ rainfall. In the days before the flood, substantial rainfall occurred, bringing the catchment to saturation. The reported peak discharge at Balingen is $350 \mathrm{~m}^{3} \mathrm{~s}^{-1}$, i.e. $2.7 \mathrm{~m}^{3} \mathrm{~s}^{-1} \mathrm{~km}^{-2}$; the event claimed the lives of 40 people. According to the available regional flood frequency analyses, this flood peak exceeded $1000 \mathrm{yr}$ return period (which is around $210 \mathrm{~m}^{3} \mathrm{~s}^{-1}$ for this catchment). A second catastrophic flood is reported for the Echaz catchment $\left(133 \mathrm{~km}^{2}\right.$, near the Starzel basin) on 20 May 1906, with $135 \mathrm{~m}^{3} \mathrm{~s}^{-1}$. Overall, this shows the relevance of floods triggered by organized systems of short, convective events for the study region, mainly occurring during late spring/summer season.

\section{The flash flood of 2 June 2008}

The rainstorm that triggered the flash flood of the Starzel River was part of a sequence of mesoscale precipitation systems (called Hilal) which occurred from 28 May to 2 June 2008 covering most of Western Germany. The Hilal organised system of thunderstorms formed along a stationary air mass boundary separating warm, moist Mediterranean air in the southwest from dry air in the northeast. The first system occurred on 28 May and was focused on MidWest Germany (city of Dortmund), about $800 \mathrm{~km}$ NorthWest from the Starzel area. A second system occurred on 29-30 May, causing flooding in Luxembourg, RhinelandPalatinate, and North Rhine-Westphalia. On the evening of 2 June, torrential storms led to flash flooding and inundation in Baden-Württemberg, with extreme rain intensities in parts of the Neckar basin. The Starzel catchment closed at Rangendingen was struck by the flood. The storm was very localised in space and characterised by strong spatial gradients and motion. The soil moisture conditions at the start of the event were relatively wet, given the precipitation in the previous days. The month of May 2008 was not particularly wet, with a rain depth measured in Hechingen equal to $85.1 \mathrm{~mm}$, to be contrasted with a climatological 1961-1990 mean of $108.2 \mathrm{~mm}$. However, more than half the monthly rain was concentrated in the last two days, as a consequence of the system of heavy storms which characterized the period 28 May-2 June 2008. The flood was not associated with landsliding or debris flow, due to both the morphological characteristics of the catchment (with relatively short hillslopes) and the short character of the rain event which likely prevented the formation of the high pore water pressure required for slope instability. Only a few shallow slope failures and landslides were documented on the catchment area most impacted by the storm close to the town of Jungingen.

The Starzel river flows through the towns of Jungingen, Hechingen and Rangendingen, which were flooded with damage to roads, buildings and infrastructures; three people died as a consequence of the flood in Jungingen and in Hechingen.

\section{Rainfall estimation and analyses}

\subsection{Rainfall data and spatial distribution}

Radar and rain gauge observations were used to derive rainfall fields for the 2 June 2008 storm. The rainfall observation resources include two volume-scanning Doppler Cband radar located at Türkheim and Feldberg (Fig. 1), about 60 and $90 \mathrm{~km}$ off the study watershed, respectively. The region impacted by the storm has a limited extension: only 4 hourly rain gauges could be used to check the radar-based estimates (Fig. 1). Data from the original volume scan data (which include 18 elevations, with time resolution of $5 \mathrm{~min}$, 
and spatial resolution of $250 \mathrm{~m}$ in range by 1.0 degree in azimuth) were made available by DWD for radar rainfall estimation. This permitted the application of an integrated set of procedures, aiming at detecting and correcting the following errors: (i) partial beam occlusion; (ii) signal attenuation; (iii) vertical profile of reflectivity (VPR); (iv) radar hardware miscalibration. The correction procedures are described in detail by Bouilloud et al. (2009) for a different case study; a summary is provided below. Due to the extremely high rain rates, and the characteristics of the weather radar, specific attention was paid to the correction of the signal attenuation by means of the Mountain Reference Technique (MRT, hereinafter) (Delrieu et al., 1997; Serrar et al., 2000). By applying the MRT, maximum Path Integrated Attenuation (PIA, hereinafter) between 8 and $14 \mathrm{~dB}$ were measured for path-averaged rain rates between 10 and $15 \mathrm{~mm} \mathrm{~h}^{-1}$ over a $50-\mathrm{km}$ path. By considering the PIA constraint equation, the MRT allowed estimation of an effective radar calibration correction factor, assuming a drop size distribution model and the subsequent reflectivity-rain rate-attenuation relationships to be known. At each time step, the radar observations from either Türkheim or Feldberg were used depending on the computed attenuation, with a preference given to data from Türkheim because of the closer proximity of this antenna to the study area. Due to the presence of hail, a rain-rate threshold (hail cap) parameter was also imposed. It should be noted that hail occurrence may induce errors in the application of the MRT, due to the violation of the drop size distribution homogeneity assumption. However, the MRT has been shown to be robust with respect to hail contamination in past studies (Serrar et al., 2000). Besides signal attenuation, screening effects were quantified using a numerical model of radar beam propagation in the atmosphere and the terrain model of the region. The vertical structure of reflectivity was modelled with the normalized apparent VPR estimated over the whole radar volume. The final step of the processing chain consisted of generating 15-min rainfall accumulation over a 1-km Cartesian grid from the instantaneous surface rainfall rate estimation. To account for the bias, the final rainfall accumulations were scaled with a spatially uniform bias factor, computed by comparing the adjusted radar estimates and the raingauge values at the event aggregation scale.

Radar-rainfall estimates obtained in this way were evaluated by comparing them with rain gauge observations at the hourly aggregation scales (which were considered as reference values, Fig. 4). The statistical assessment was carried out in terms of Relative Mean Absolute Error (equal to 0.48) and Correlation Coefficient (equal to 0.90). The mean error is null, due to the use of the event-cumulated raingauge data for bias correction. These results show that, given the constraint provided by the bias correction, the radar-rainfall estimates correctly reproduce the precipitation spatial and temporal repartition detected by raingauges at the hourly temporal resolution.

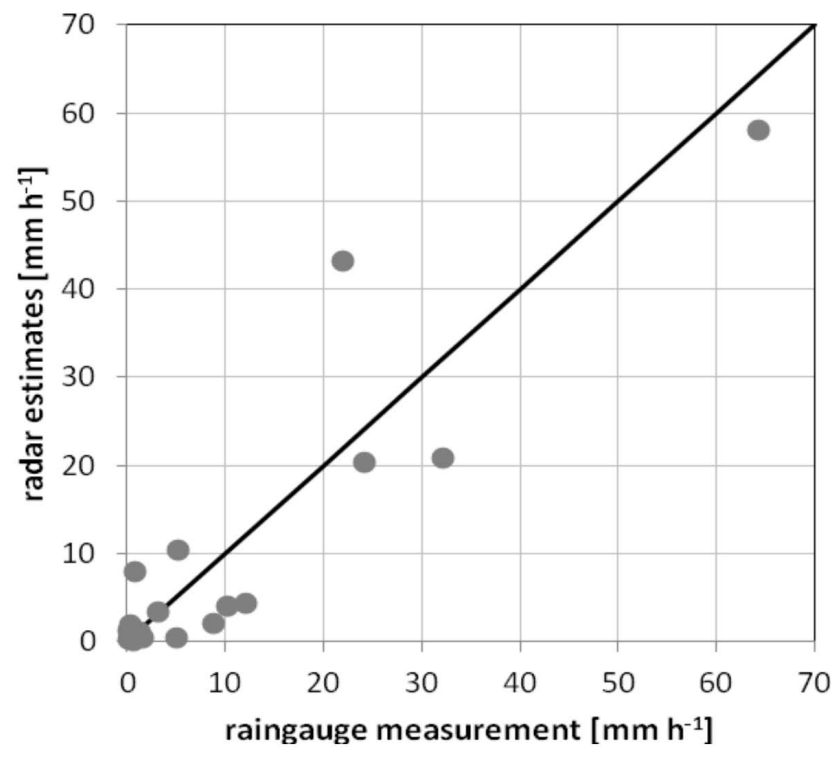

Fig. 4. Scatter plot of adjusted radar rainfall estimates versus raingauge measurements for hourly accumulations.

Even though the radar estimates and raingauge measurement compare well, the uncertainties in reproducing fine features of the highly variable precipitation pattern need to be acknowledged. This is mainly related to the difficulties arising with the adjustment for the signal attenuation effects, which were particularly severe for this event.

The spatial distribution of the event-cumulated rainfall depth over the Starzel catchment at Rangendingen is reported in Fig. 5, which shows that the largest rainfall amounts are localised on the central and lower portions of the catchment, with very large values over the eastern tributaries.

The distribution of exceedance areas, i.e. the areas over which various rain thresholds were exceeded, is reported in Fig. 6, which shows that the most important rainfall amounts, exceeding $100 \mathrm{~mm}$, impacted just around $30 \%$ of the catchment.

Measuring rainfall for storms that produce extreme localized floods is fraught by large uncertainties. The 2 June 2008 flood provides a useful illustration of this uncertainty. Information concerning the amount and the timing of the strong rainfall was collected by a weather amateur resident in Jungingen (Mr. Heizelmann). Mr. Heizelmann's rain gauge is located on a fence $1.5 \mathrm{~m}$ high in his garden in an appropriate position for a reasonably accurate measurement of rainfall. According to his observations, the rain amount exceeded $240 \mathrm{~mm}$ in $55 \mathrm{~min}$. This rain amount is significantly higher than the corresponding co-located radar estimate, which points to uncertainty either on the adjustment of the radar estimates or on the accuracy of the rain measures by the local observer. Moreover, sampling effects due to the differences between the radar volume and the raingauge point measure may explain part of the large difference. The value 


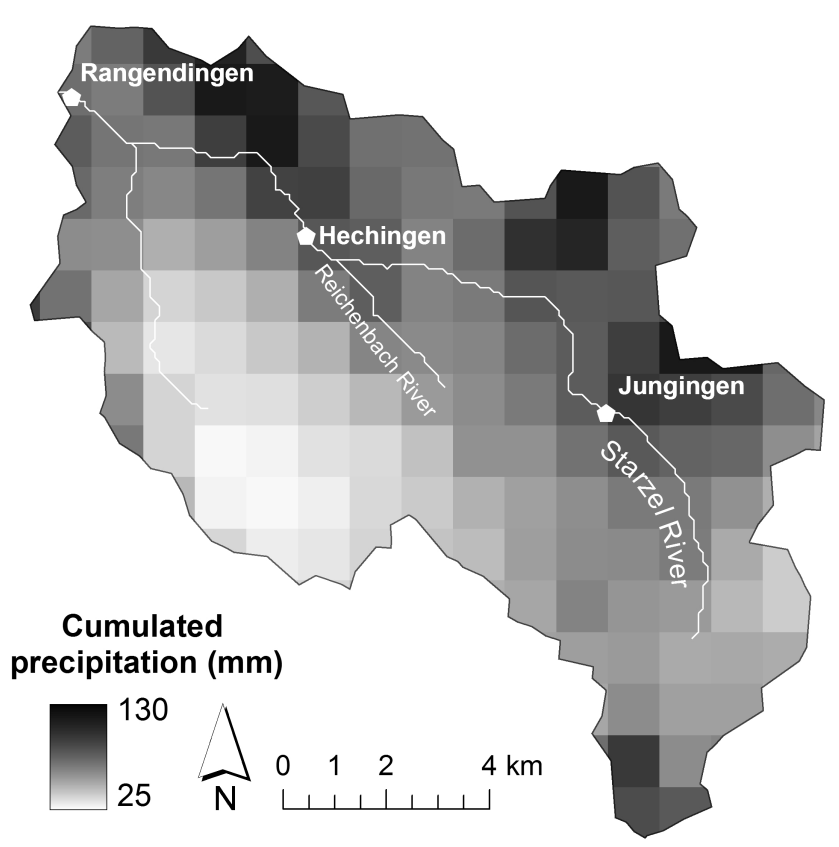

Fig. 5. Event-cumulated rainfall spatial distribution over the Starzel catchment at Rangendingen.

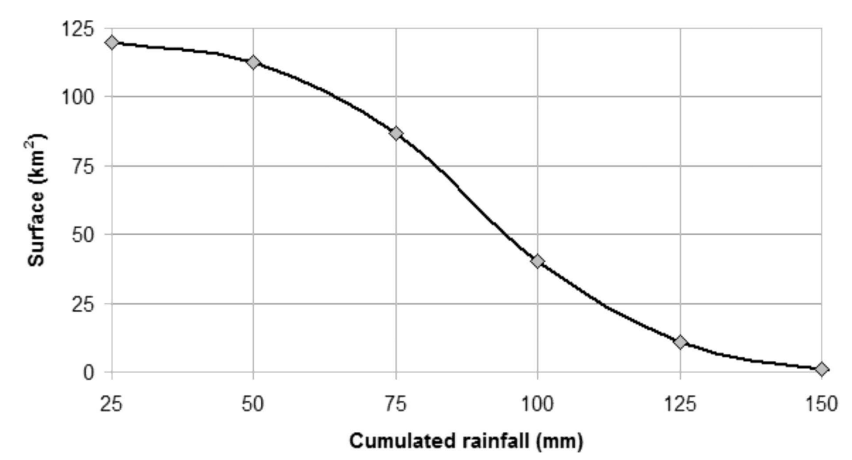

Fig. 6. Distribution of exceedance areas, i.e. the areas over which the event-cumulated rainfall exceeded various thresholds.

of $240 \mathrm{~mm}$ in $55 \mathrm{~min}$ is an extreme rainfall depth, which can be compared to the world record accumulation of $305 \mathrm{~mm}$ in 42 min recorded in Holt, Montana, on 22 June 1947. The rain observations by Mr. Heizelmann could not be validated and have not been used in this work but are reported as an indication of the potential uncertainties in rainfall estimation for extreme convective events.

The analysis of the mean areal rainfall depth over the basin at Ragendingen provides a value of $85.6 \mathrm{~mm}$ for the entire storm event, and of $55.5 \mathrm{~mm}$ for the $90 \mathrm{~min}$ corresponding to highest intensities. A statistical analysis based on the KOSTRA methodology (DWD, 2006) shows that the observed $90 \mathrm{~min}$ rainfall corresponds to a $100-\mathrm{yr}$ recurrence interval. However, the recurrence interval of the entire event $(85.6 \mathrm{~mm}$ in $10 \mathrm{~h}$ ) is more extreme. The 100 -yr rainfall of 10 hours duration according to DWD (2006) amounts to $67.6 \mathrm{~mm}$. Ex- amination of the quantiles corresponding to $1000-y r$ recurrence interval indicates that the rainfall was well beyond a 100 -yr, but below a 1000 -yr event. This corresponds also to the return period of the field-estimated discharge.

\subsection{Space-time rainfall variability and storm motion}

The spatial and temporal rainfall characteristics are examined here by using the spatial moments of catchment rainfall (Zoccatelli et al., 2011). As a detailed description of the method and of its assumptions is reported in Zoccatelli et al. (2011), only an outline of the method is given here. With these statistics, rainfall spatial variability is examined relative to a distance metric imposed by the so-called "flow distance", i.e. the distance along the drainage path from a generic point within the basin to the outlet of the basin drainage network. The use of the flow distance is motivated by the observation that runoff routing imposes an effective averaging of spatial rainfall excess across locations with equal routing time, in spite of the inherent spatial variability. The flow distance may be used as a surrogate for runoff travel time, when hydrodynamic dispersion and variations in runoff propagation celerities can be neglected. The first scaled spatial moments of catchment rainfall at time $t$, indicated with $\delta_{1}(t)$, is computed as follows:

$\delta_{1}(t)=\frac{\int_{A} r(x, y, t) d(x, y) d A}{\int_{A} r(x, y, t) d A \cdot A^{-1} \int_{A} d(x, y) d A}$

where $r(x, y, t)$ is the rainfall rate at position $(x, y)$ in the basin and time $t, d(x, y)$ is the flow distance, and $A$ is the basin area. The mean value of the flow distance over the basin is denoted with $g_{1}$ hereinafter.

Accordingly with these definitions, the first scaled moment $\delta_{1}$ represents the ratio between the mean rainfall weighted flow distance and the product of the mean areal rainfall rate and the mean value of the flow distance. A spatial rainfall distribution either concentrated close to the position of mean flow distance or spatially uniform results in values of $\delta_{1}$ close to 1 . A value of $\delta_{1}$ less than one indicates that rainfall is distributed towards the basin outlet, whereas a value greater than one indicates that rainfall is distributed towards the headwaters.

Equation (1) can also be extended to describe the spatial rainfall organization corresponding to the cumulated rainfall over a certain time period $T_{\mathrm{s}}$ (e.g. a storm event), obtaining the statistic termed $\Delta_{1}$. Zoccatelli et al. (2011) showed that, when the temporal integration corresponds to the floodgenerating storm event, it is possible to relate the value of $\Delta_{1}$ with the shape of the hydrograph. A less-than-one value of $\Delta_{1}$ (which means that rainfall is concentrated towards the outlet) results in an anticipation of the mean hydrograph time with respect to the same hydrograph obtained by a spatially uniform storm. A greater-than-one value of $\Delta_{1}$ (which means 
that rainfall is concentrated towards the headwater) results in a delay of the mean hydrograph time.

The product $\delta_{1} g_{1}$ represents the distance from the rainfall centroid to the catchment outlet. Examination of the changes in time of this distance permits calculation of an instantaneous catchment-scale storm velocity along the river network, as follows:

$V_{\mathrm{S}}(t)=g_{1} \frac{\mathrm{d}}{\mathrm{d} t} \delta_{1}(t)$

The concept of the catchment-scale storm velocity defined by Eq. (2) provides a mapping of storm motion over catchment morphology, taking into account the relative catchment orientation and geometry with respect to storm motion. A positive (negative) value of the catchment-scale storm velocity $V_{\mathrm{s}}$ indicates an increase (decrease) over time of the distance from the rainfall of the storm centroid to the outlet, hence upbasin (downbasin) storm movement. In this work, we will not perform any explicit derivative of $\delta_{1}$ to obtain the catchment scale storm velocity. While Eq. (2) has been introduced to formally represent the concept of catchmentscale storm velocity and how this relates to the first scaled moment $\delta_{1}$, we will use the methodology introduced by Zoccatelli et al. (2011) to compute the specific values, as follows:

$V_{\mathrm{S}}=g_{1} \frac{\operatorname{cov}_{t}\left[T, \delta_{1}(t) w(t)\right]}{\operatorname{var}[T]}-g_{1} \frac{\operatorname{cov}_{t}[T, w(t)]}{\operatorname{var}[T]} \Delta_{1}$

where $T$ is time, $\operatorname{cov}_{t}[]$ denotes the temporal covariance operator and var[ ] denotes the variance. The reader is referred to Zoccatelli et al. (2011) and Viglione et al. (2010) for the use of the $\operatorname{cov}_{t}[]$ and var[ ] operators. Please note that time $T$ is considered as a random variable uniformly distributed (see Appendix A.4 in Viglione et al., 2010). The rainfall weights $w(t)$ are obtained as the ratio between the instantaneous mean areal rainfall rate and the mean value of the basin-averaged rainfall rate over the storm event.

Equation (3) shows that the storm velocity is defined as the difference between the slope terms of two linear regressions with time (Zoccatelli et al., 2011). The first slope term is estimated based on the space-time regression between weighted scaled first moments and time, and the second term is based on the regression between weights and time. Conceptually, this means that storm motion may produce changes both in the rainfall centroid coordinate and in the mean areal rainfall values. Both are taken into account in the estimation of the catchment scale storm velocity. For the case of temporally uniform mean areal rainfall, $w(t)$ is constant and the value of $V_{\mathrm{s}}$ depends only on the evolution in time of the position of the rainfall centroid along the flow distance coordinate. For storm characterised by a constant value of $\delta_{1}(t)$ and temporal variation of the mean areal rainfall, the two slope terms will be equal in value and opposite in sign, which means that the $V_{\mathrm{s}}$ will be equal to zero. Note that the sign of the velocity is positive (negative) for the case of upstream (downstream) storm motion.

The 15-min time series of $\delta_{1}(t)$ and $V_{\mathrm{S}}(t)$ are reported in Fig. 7 for the catchment closed at Rangendingen, together with the time series of the mean catchment rainfall rate and of the fractional coverage of the basin by rainfall rates exceeding $20 \mathrm{~mm} \mathrm{~h}^{-1}$, where this threshold has been selected to indicate a flood-producing rainfall intensity. For the computation of the spatial moments, as well as for the hydrological model application reported below, the 1-km radar rainfall estimates were re-mapped over the $90-\mathrm{m}$ grid size digital elevation model available for the study region.

The temporal distribution of mean areal rainfall in Fig. 7a shows two main storms. The first, with 15 -min peak rain rate around $20 \mathrm{~mm} \mathrm{~h}^{-1}$, lasted between 16:00 and 17:15 CET; the second storm was much more intense (peak rain rate around $50 \mathrm{~mm} \mathrm{~h}^{-1}$ at $15 \mathrm{~min}$ time intervals) and occurred between 18:00 and 19:30CET. During the second storm rain rates exceeded $20 \mathrm{~mm} \mathrm{~h}^{-1}$ on more than $75 \%$ of the catchment.

Examination of the time series of $\delta_{1}(t)$ shows that during the first storm the precipitation was mainly concentrated around the catchment geomorphological centroid. Around 17:15-17:30 CET rain rates decrease and the rainfall centroid shifts suddenly to the headwaters of the catchment. The second storm is less localised, with a centroid moving regularly from the far periphery of the basin to positions close to the outlet. This originates a downbasin catchment scale storm motion, which reaches a steady velocity around $0.7-$ $0.9 \mathrm{~m} \mathrm{~s}^{-1}$ in the period between 17:45 and 19:30 CET, characterised by the highest rain rates. According to the literature (Ogden et al., 1995; Seo et al., 2012), the downbasin storm velocity may have added to the severity of the storm, giving rise to a stronger flood peak than that of an equivalent stationary storm characterised by the same temporal rainfall distribution and by the same value of $\Delta_{1}$.

\section{The post event survey and indirect peak discharge estimation}

The Starzel river catchment is equipped with a streamgauge station at Rangendingen, but the recorded maximum stage during the event exceeds by far the stages for which direct current meter measurements are available. The streamgauge and parts of the floodplain upstream the section were inundated during the flood, so that the maximum recorded stage value (corresponding to around $80 \mathrm{~m}^{3} \mathrm{~s}^{-1}$ according to the current rating curve) was considered to underestimate the high discharges, and especially the flood peak. An indirect flood peak estimate, based on analysis of flood traces in nonoverflooded river sections upstream the streamgauge station was carried out just after the flood by the Baden-Württenberg hydrological services (Markus Moser, local Water Authority, personal communication, 2008). The indirect flood peak 

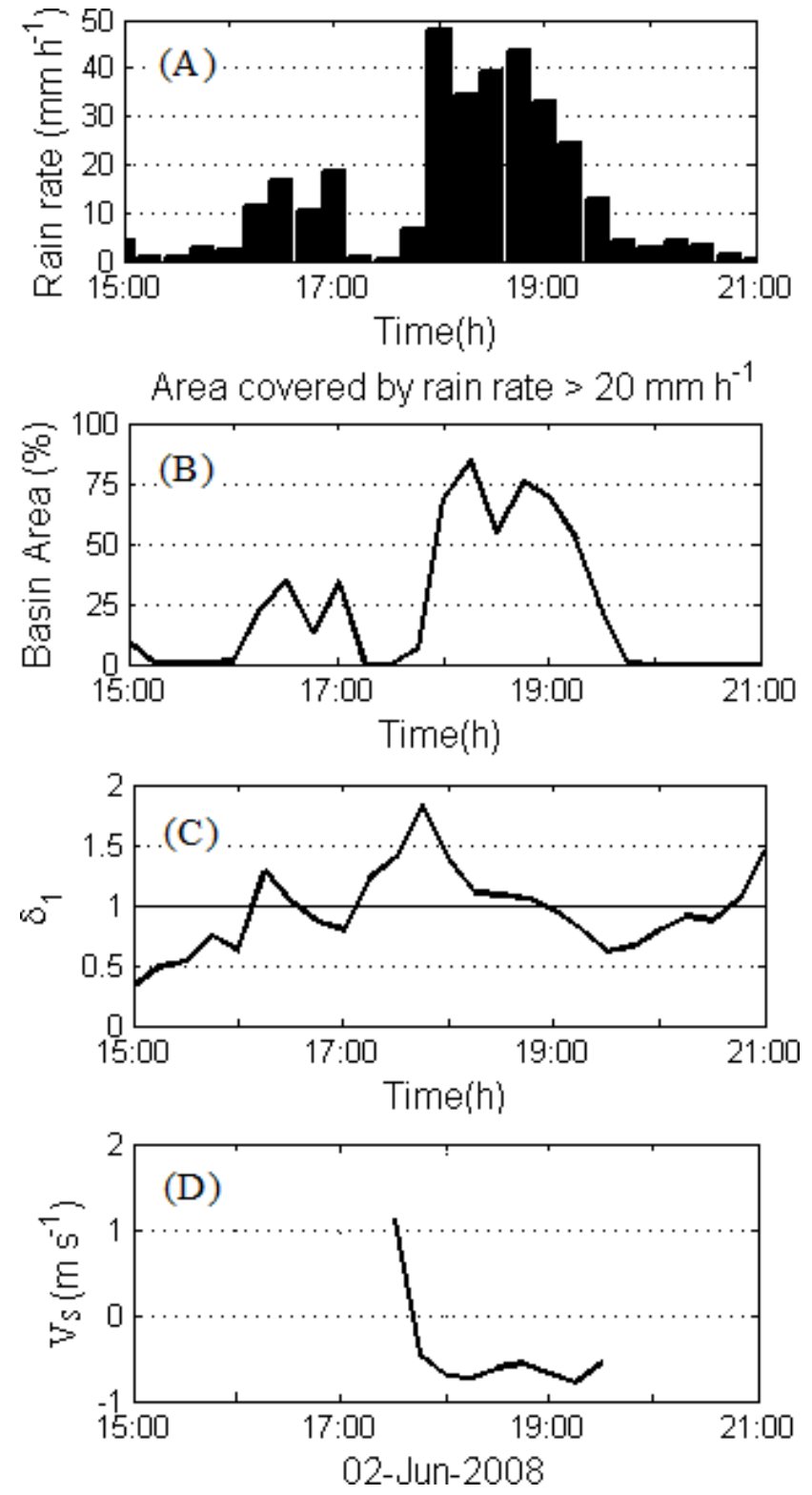

Fig. 7. Starzel catchment at Rangendingen: precipitation analyses by using 15-min time series of (a) precipitation intensity, (b) percent coverage of the catchment (for precipitation intensity $>20 \mathrm{~mm} \mathrm{~h}^{-1}$ ), (c) $\delta_{1}$, (d) catchment scale storm velocity.

estimate provided an assessment of peak flow between 120 and $155 \mathrm{~m}^{3} \mathrm{~s}^{-1}$.

A post-flood survey campaign (denoted IPEC, Intensive Post-Event Campaign, hereinafter) was organised in the period 10-14 November 2008 with the main objective to examine the spatially distributed flood response properties to the storm. The field work included surveying of High Water Marks (HWM), water surface slope and cross-sectional geometry at multiple sites along the river network. These data were used to estimate indirectly the flood peaks by means of hydraulic equations. The IPEC was organised in the frame of the European Project HYDRATE (http://www.hydrate.tesaf. unipd.it), funded by the EU Commission, Sixth Framework Programme (Borga et al., 2011), with the collaboration of local authorities. Even though 6 months passed between the date of the flood and that of the field survey, the HWM were still clearly recognisable. Also, the stream bed morphology (which is typical of a bedrock river in many sectors of the channel network) was not severely modified by the flood. This gives confidence in using the post-flood geometry for flood peak computation. Thirty-three cross-sections were surveyed during the field campaign and peak discharges were assessed using the slope-conveyance method (Gaume and Borga, 2008; Marchi et al., 2009). The location of the cross sections is reported in Fig. 2. The discharge estimates help mapping the flood responses along the Starzel River, its main tributary the Reichenbach, as well as the contribution of parts of their tributaries. A selection of the original cross section data, concerning 17 sections (called "Sites" hereinafter) which are at reasonable distance each other along the same river reach, thus providing relatively independent information, is reported in Table 1.

Indirect peak discharge estimates are potentially affected by a range of uncertainties, which may be induced by errors in HWM assessment and in the choice of roughness coefficients, in the use of the post-flood geometry and its survey, in the assumptions concerning the energy line slope, and by possibly undetected backwater effects.

Uncertainty ranges reported in Table 1 account for the uncertainty in the selection of the Manning roughness parameter and in the energy slope estimation, in the form of a $95 \%$ uncertainty range. This leads to underestimate the actual uncertainty in indirect peak discharge estimation. However, a complete quantitative treatment of the uncertainty involved in the survey is not a central objective of this paper and will be reported in future works.

Despite the mentioned sources of uncertainties, the values reported in Table 1 appear to be consistent with each other. The peak discharge increases steadily from the headwaters to Jungingen. Downstream Jungingen, the field-observed peak discharges are around $120-170 \mathrm{~m}^{3} \mathrm{~s}^{-1}$ in the reaches upstream Rangendingen, with a value in Site 3 which appears relatively higher than downstream sections even accounting for uncertainty. The inundation of the town of Hechingen may have had an attenuating effect on the flood wave of the Starzel river. The peak discharge indirect estimates in Ragendingen corresponds to a return time around $100 \mathrm{yr}$ (which is estimated at $160 \mathrm{~m}^{3} \mathrm{~s}^{-1}$ for a basin area of $120 \mathrm{~km}^{2}$ in the study region).

The chronology of the start of overflooding and of the peak stage was also investigated based on the witnesses' interviews and movies recorded by eye-witnesses of the flood. In Jungingen, the sequence of the events was reconstructed as follows (timing is given here in local solar time, i.e. CET): "around 18:15 CET, river level in Jungingen rose from bankfull to peak, with around $1.2-1.5 \mathrm{~m}$ of water in 
Table 1. Peak discharge estimates from the field survey. Section reference numbers are reported in Fig. 1.

\begin{tabular}{rrrrr}
\hline Ref. & $\begin{array}{r}\text { Watershed } \\
\text { area } \\
\left(\mathrm{km}^{2}\right)\end{array}$ & $\begin{array}{r}\text { Mean flow } \\
\text { velocity }\left(\mathrm{m} \mathrm{s}^{-1}\right) \\
(\text { central value })\end{array}$ & $\begin{array}{r}\text { Peak discharge } \\
(\text { central value) } \\
\left(\mathrm{m}^{3} \mathrm{~s}^{-1}\right)\end{array}$ & $\begin{array}{r}\text { Peak discharge } \\
(\text { uncertainty range }) \\
\left(\mathrm{m}^{3} \mathrm{~s}^{-1}\right)\end{array}$ \\
\hline 1 & 9.5 & 2.8 & 9. & $6 .-12$. \\
3 & 53.9 & 2.3 & 150. & $130 .-170$. \\
4 & 119.8 & 2.5 & 150. & $125 .-175$. \\
6 & 47.4 & 3.7 & 120. & $105 .-135$. \\
7 & 85.7 & 2.6 & 165. & $150 .-180$. \\
10 & 1.0 & 1.5 & 3.5 & $3 .-4$. \\
12 & 1.1 & 1.4 & 6.5 & $6 .-7$. \\
14 & 26.0 & 2.4 & 23. & $20 .-26$. \\
15 & 29.0 & 2.5 & 33. & $28 .-38$. \\
16 & 29.4 & 2.9 & 45. & $35 .-55$. \\
22 & 33.2 & 3.3 & 65. & $53 .-77$. \\
24 & 37.6 & 2.3 & 90. & $70 .-110$. \\
25 & 2.2 & 3.0 & 8. & $6 .-10$. \\
26 & 2.1 & 2.5 & 25. & $20 .-30$. \\
32 & 1.6 & 2.5 & 3.0 & $1.5-4$. \\
33 & 17.8 & 3.4 & 20. & $15 .-25$. \\
37 & 1.9 & 2.6 & 11. & $8 .-14$. \\
\hline
\end{tabular}

the streets. The river reached the peak at around 18:45 CET, maintaining the level for around $20 \mathrm{~min}$. Between 20:00 and 20:30 CET the river stage reduces to the embankment level." Overall this agrees with the information provided by the rainfall sequence.

\section{Rainfall-runoff analysis}

\subsection{Relationships between field-derived peak flows and rain properties}

The relationship between the distribution of the fieldobserved unit peak discharges and the properties of the rainfall forcing is reported in Fig. 8. For each surveyed basin, three basin-averaged rainfall characteristics are reported and analysed: the event cumulated rainfall, the maximum hourly rainfall and the maximum 30-min rainfall. Not surprisingly, the highest values of unit peak discharge are observed in the smallest catchments (area less than $10 \mathrm{~km}^{2}$ ). In particular, the Sites 12, 26 and 37 (all corresponding to catchment areas in the range of 1.1 to $2.1 \mathrm{~km}^{2}$ ), located in the area affected by the most intense rainfalls, are characterised by very high values of unit peak discharge. These values are around $5.8 \mathrm{~m}^{3} \mathrm{~s}^{-1} \mathrm{~km}^{-2}$ for Sites 12 and 37 and around $12 \mathrm{~m}^{3} \mathrm{~s}^{-1} \mathrm{~km}^{-2}$ for Site 26 . These are extreme values for the study area.

The pattern of the relations between precipitation and unit peak discharge is very similar for cumulated storm precipitation and 1-h maximum rainfall intensity. This can be ascribed to the close correlation between total event rainfall and 1-h maximum rainfall, which becomes lower when 30-min rain- fall is considered (Fig. 9 a and b). For instance, catchments $10,12,25$ and 26 have very similar event-cumulated rain depths and max 1-h rain depths. However, max 30-min rain depths are less than $90 \mathrm{~mm} \mathrm{~h}^{-1}$ for catchments 10 and 12 , and close to $130 \mathrm{~mm} \mathrm{~h}^{-1}$ for catchments 25 and 26 .

Small catchments induce a large scatter in the relationship presented in Fig. 8. For instance, catchments 25 and 26 are characterised by very similar rain depths (127.2 and $127.3 \mathrm{~mm}$, respectively) and intensities, they are very close to each other and have very similar size (around $2 \mathrm{~km}^{2}$ ). However, field-estimated flood peak from catchment 26 is almost three times that reported for catchment 25 . Even the field-estimated flow velocity is very similar (Table 1), which means that the main difference between the two estimates is in the surveyed HWM and section geometry. Possible explanations for such differences include the difficulty to correctly estimate the watershed area for these small catchments. The watershed area was estimated based on a digital elevation model of $90 \mathrm{~m}$ grid size, which is adequate for the main objectives of this study and for the size of the Starzel basin, but is rather rough for basin size as small as $1 \mathrm{~km}^{2}$.

When examination of the values reported in Fig. 8 is limited to catchments larger than $10 \mathrm{~km}^{2}$, a relatively good relationship is found between specific unit peak flow and the rain event-accumulation and 1-h maximum. However, the linear pattern is lost when 30 min maximum rain is considered, showing that this rain property bears limited influence on catchment response for basins larger than $10 \mathrm{~km}^{2}$. This is not a surprising result, since the time of concentration of watersheds exceeding $10 \mathrm{~km}^{2}$ is higher than $30 \mathrm{~min}$, according to the analyses carried out in the study. 

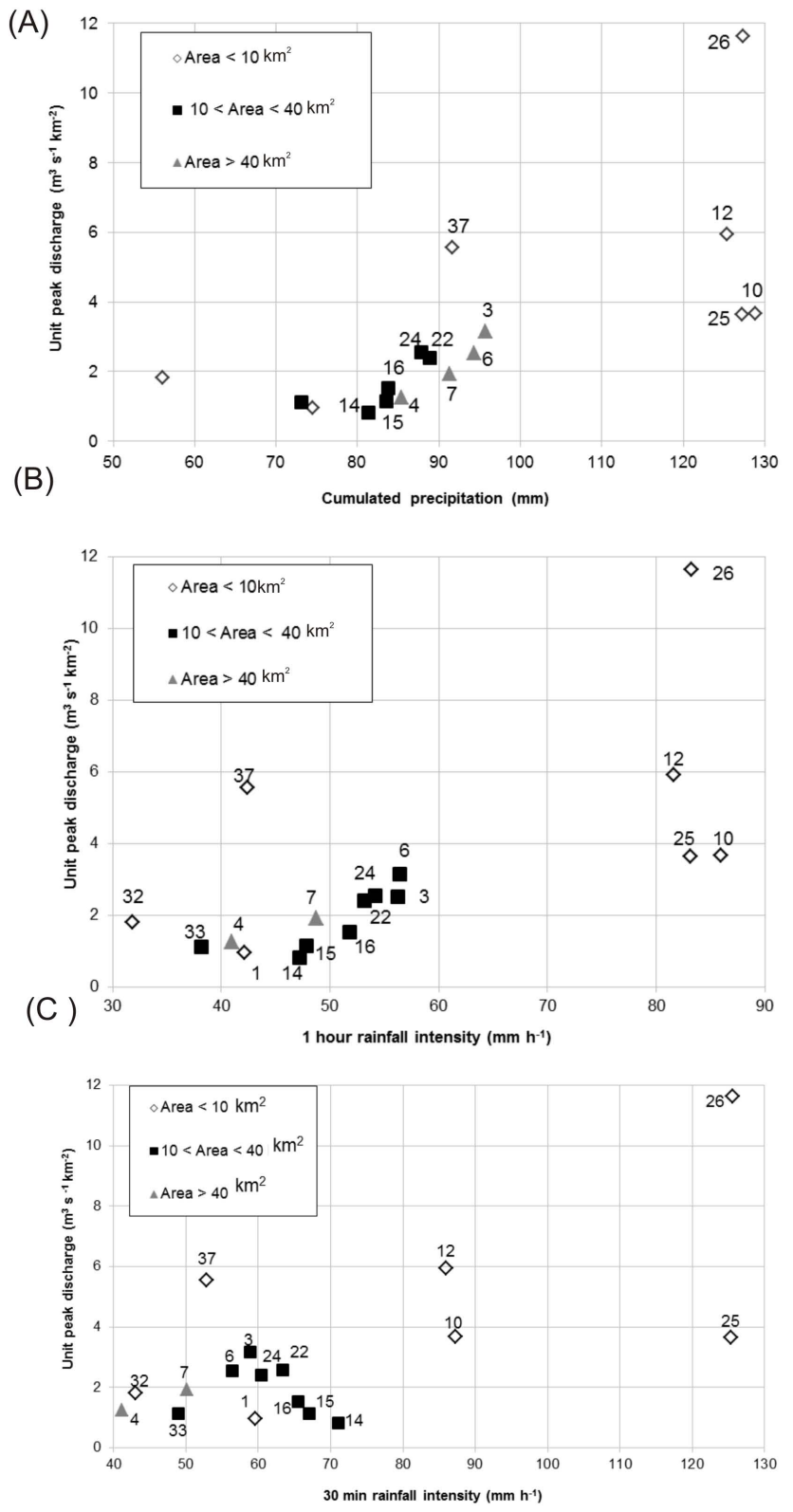

Fig. 8. Relationship between estimated unit peak discharges and rainfall characteristics for the 17 IPEC catchments: (a) event cumulated rainfall; (b) max. 1-h rainfall intensity; (c) max. 30-min rainfall intensity. The numbers refer to the basins listed in Table 1 .

\subsection{Rainfall-runoff modelling and analysis of runoff ratios}

Hydrologic response to the June 2008 storm is examined by using a spatially distributed hydrologic model. Three main objectives are pursued with this model application: (i) analysis of the accuracy in simulating the spatially distributed runoff response when applying model calibration at the outlet sections in Rangendingen and Jungingen; (ii) examination of the hydrologic consistency of the field-derived peak dis-
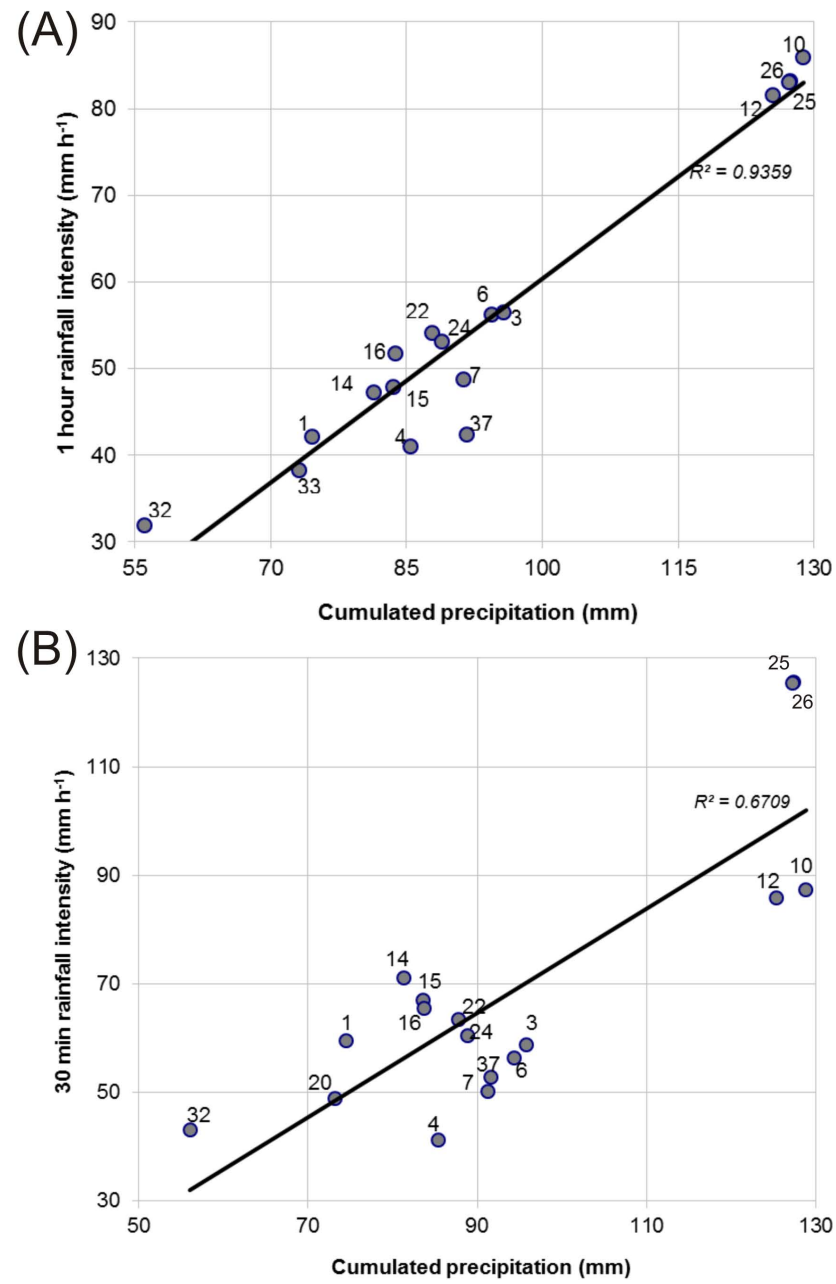

Fig. 9. Relationship between the event-cumulated rainfall depth and the 1-h peak (a) and 30-min peak (b) rainfall intensity for the 17 IPEC catchments.

charges; and (iii) assessment of the impact of the rainfall variability on the simulated flood hydrographs at Rangendingen.

The hydrological model is described in detail in Zanon et al. (2010) and only an outline is provided here. The discharge $Q(t)$ is computed by the model at any location along the river network as follows:

$Q(t)=\int_{A} q[x, y, t-\tau(x, y)] d A$

where $A$ indicates the area draining to the specified outlet location, $\tau(x, y)$ is the routing time from the location $(x, y)$ to the outlet of the basin specified by the region and $q(x, y, t)$ is the runoff rate at time $t$ and location $x, y$. The runoff rate is computed from the rainfall rate $r(x, y, t)$ using the GreenAmpt infiltration model with moisture redistribution (Ogden and Saghafian, 1997). The routing time $\tau(x, y)$ is computed as 
$\tau(x, y)=\frac{d_{\mathrm{h}}(x, y)}{v_{\mathrm{h}}}+\frac{d_{\mathrm{c}}(x, y)}{v_{\mathrm{c}}}$

where $d_{h}(x, y)$ is the distance from the generic point $x, y$ to the channel network following the steepest descent path, $d_{\mathrm{c}}(x, y)$ is the length of the subsequent drainage path through streams down to the watershed outlet. $v_{\mathrm{h}}$ and $v_{\mathrm{c}}$ are two invariant hillslope and channel flood celerities, respectively. The use of invariant channel and hillslope celerities requires some clarification. Pilgrim (1976), using tracer studies, showed that the average flow velocities are a nonlinear function of the discharge, but reach an asymptotic value at high flows. This supports the assumption that models of the hydrologic response employing invariant channel celerity explain observed travel time distributions, at least for high flows conditions. The invariant hillslope celerity assumption is more conceptual in nature (Botter and Rinaldo, 2003). In fact, great variability in hillslope transport properties is expected, particularly when it is driven by local topographic gradients as subsurface runoff through partially saturated areas and in the presence of preferential flow paths (e.g. Beven and Wood, 1983; Dunne, 1978).

The model includes also a linear conceptual reservoir for base flow modeling (Borga et al., 2007). The reservoir input is provided by the infiltrated rate computed based on the Green-Ampt method.

The model requires estimation of seven calibration parameters: the channelization support area $\left(A_{\mathrm{s}}\right)$, two kinematic parameters $\left(v_{\mathrm{h}}\right.$ and $\left.v_{\mathrm{c}}\right)$, the three soil hydraulic parameters used by the Green-Ampt method and the time constant of the conceptual linear reservoir. The model was implemented over the Starzel catchment at 15-min time step and using a $90 \mathrm{~m}$ grid size cell for the description of landscape morphology and soil properties. The most sensitive model parameters (saturated hydraulic conductivity, flow velocity parameters and the time constant of the conceptual linear store) were manually calibrated based on the flood peak estimated in Rangendingen and on the information concerning the chronology of the flood collected in Rangendingen and in Jungingen. The manual calibration aimed to minimise (i) the error in the time of the rising hydrograph, (ii) the error in peak discharge and peak time, and (iii) the error in the recession limb of the hydrograph. Information concerning the timing of the main hydrograph feature was based on eyewitnesses' assessment. Uncertainty analysis of this kind of information based on multiple crosschecked interviews shows that the timing of specific flood hydrograph features may be accurate within $\pm 20 \mathrm{~min}$ (Zanon et al., 2010).

Accordingly, the channelization support area $\left(A_{\mathrm{S}}\right)$ is found equal to $2.43 \mathrm{ha}, v_{\mathrm{c}}$ is equal to $3 \mathrm{~m} \mathrm{~s}^{-1}$ and $v_{\mathrm{h}}$ is equal to $0.05 \mathrm{~m} \mathrm{~s}^{-1}$. The value of channel celerity agrees well with field based observations of flow velocity reported in Table 1 . The value of saturated hydraulic conductivity was set equal to $10 \mathrm{~mm} \mathrm{~h}^{-1}$ in the urbanized area and to 20 and $40 \mathrm{~mm} \mathrm{~h}^{-1}$ on the areas characterized by agriculture and forest land use, respectively. The initial conditions in the Green-Ampt model were set to fit the start of rising limb of the observed flood discharges in Rangendingen.

To examine the performance of the model in simulating different floods, the model was applied to five flood events selected in the period 2002 to 2010 (Table 2). The considered floods are those exceeding a threshold of $25 \mathrm{~m}^{3} \mathrm{~s}^{-1}$ peak discharge in Rangendingen, and occurred in the following periods (date of the flood peak is reported): 4 May 2002; $11 \mathrm{Au}$ gust 2002; 21 June 2007; 18 June 2008; 23 July 2010. These are moderate events, considering the catchment flood regime. The model parameters were kept constant, with the exception of those describing the antecedent soil moisture conditions, which were calibrated to represent the start of the rising phase of the observed flood discharges. Model results were relatively good, when one takes into account that the model calibration was carried out on an extreme flood which may be representative of hydrological processes not observed during "normal" events. Observed and simulated flood hydrographs are reported in Fig. 10 for the events of 11 August 2002 and 23 July 2010, as examples of model results. The comparison shows that the timing of the flood peak is well simulated in the modeled hydrographs. On the other hand, the recession limb and the volume are less accurately portrayed. Overall, this indicates that runoff propagation is modeled in a robust way, whereas the estimation of the runoff volume in some cases is more uncertain. However, these model results shows that parameters identified on an extreme event may be transported to less extreme cases, when initial conditions are properly accounted for. Examination of the distribution of the event runoff ratio in the following sections provides a partial explanation for this finding.

Results from the model application to the June 2008 flood are reported for the catchment at Rangendingen (Fig. 11) and at Jungingen (Fig. 12). As expected, the flood hydrograph simulated in Rangendingen shows large discrepancies with respect to the one derived on the basis of the observed streamgauge data. This is related to the overflowing of the cross section and of the floodplain upstream the section. Owing to this reason, the simulated flood peak is anticipated. The chronology of the flood peak agrees with accounts reported by eyewitnesses. The hydrograph simulated at Jungingen shows a satisfactory agreement with the chronology of the flood as reported in the account of witnesses about the start of the bank overtopping, the time of flood peak and the end of the river bank overtopping (Fig. 12). For both catchments, the simulated flood peak is included in the range of indirect peak discharge estimates reported on the basis of the post-flood survey, as expected since the IPEC information was used for model calibration.

Rainfall and runoff properties are reported in Table 3 for the catchments closed at Jungingen and at Rangendingen. These data, obtained by using the field-validated model simulations, show that the runoff ratio is very low. In spite of the 
Table 2. Rainfall and runoff properties for the five flood events observed at Rangendingen between 2002 and 2010.

\begin{tabular}{|c|c|c|c|c|c|c|}
\hline Basin & $\begin{array}{l}\text { Rain } \\
(\mathrm{mm})\end{array}$ & $\begin{array}{r}\text { Runoff } \\
(\mathrm{mm})\end{array}$ & $\begin{array}{r}\text { Observed } \\
\text { peak } \\
\text { discharge } \\
\left(\mathrm{m}^{3} \mathrm{~s}^{-1}\right)\end{array}$ & $\begin{array}{r}\text { Simulated } \\
\text { peak } \\
\text { discharge } \\
\left(\mathrm{m}^{3} \mathrm{~s}^{-1}\right)\end{array}$ & $\begin{array}{r}\text { Runoff } \\
\text { ratio }\end{array}$ & $\begin{array}{r}\text { Duration } \\
\text { (h) }\end{array}$ \\
\hline 4 May 2002 & 56 & - & 26.0 & 25.5 & - & 42 \\
\hline 11 August 2002 & 78 & 19.9 & 88.0 & 85.9 & 0.25 & 17 \\
\hline 21 June 2007 & 36 & 5.2 & 45.0 & 23.9 & 0.14 & 3 \\
\hline 18 June 2010 & 53 & 11.4 & 28.0 & 30.2 & 0.21 & 16 \\
\hline 23 July 2010 & 41 & 6.8 & 48.0 & 42.8 & 0.16 & 9 \\
\hline
\end{tabular}
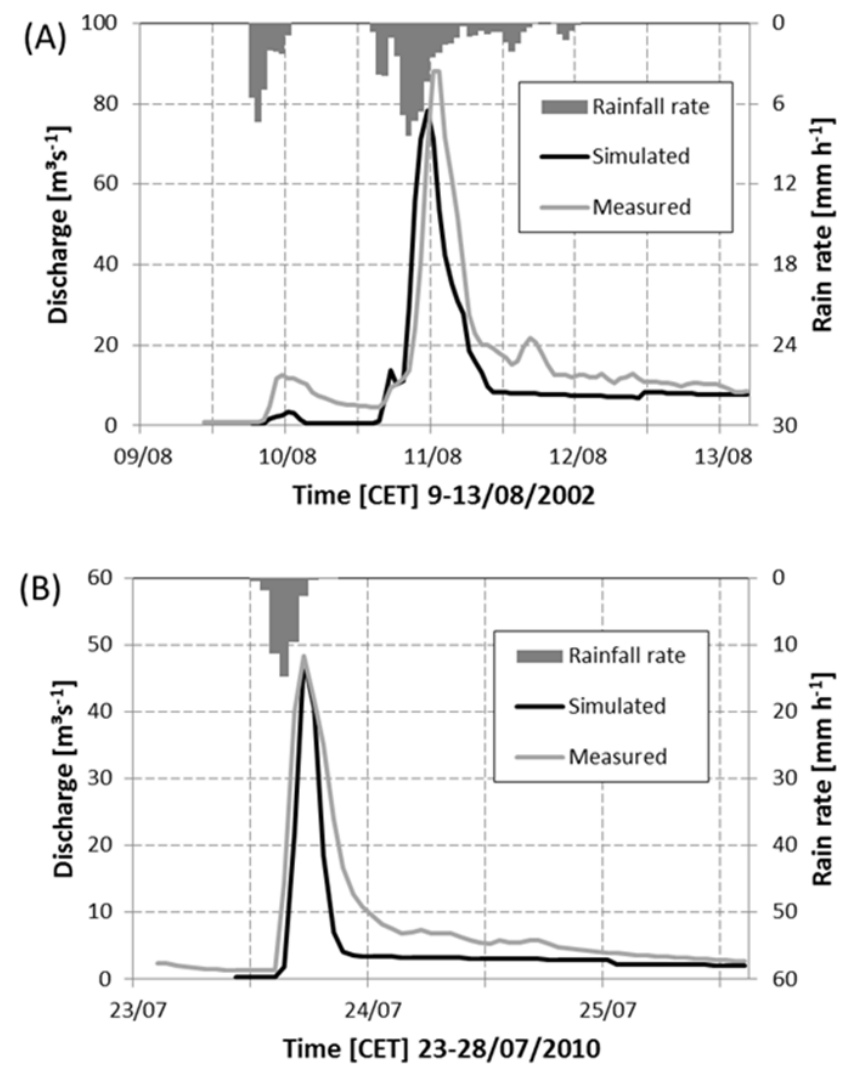

Fig. 10. Comparison between observed and simulated hydrograph at Rangendingen for two flood events occurred on: (a) 11 August 2002 and (b) 23 July 2010.

relatively wet antecedent soil moisture conditions and of the high rain rates and accumulations, runoff depth is just a small fraction of the rainfall volume, ranging from 0.13 to 0.16 . These values are in the range of those computed (based on measured data) for the five events reported in Table 2, where the runoff ratio ranges between 0.14 and 0.25 . Please note that the runoff ratio is not reported for the May 2002 flood. This flood was very long and composed of several peaks; as a result, the estimation of runoff ratio is subject to significant uncertainty. The analogy in terms of runoff ratio of the

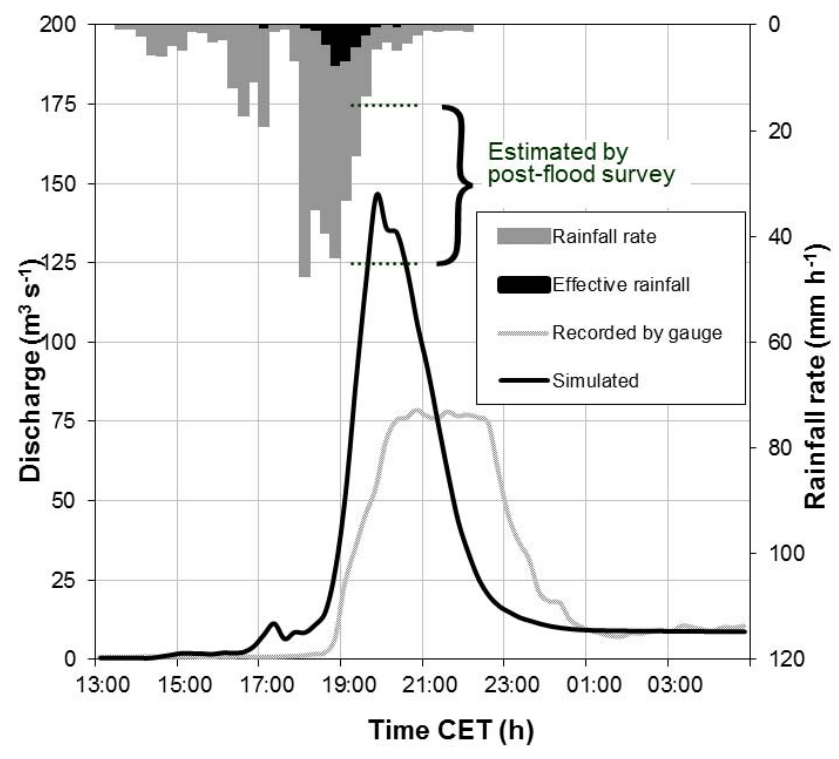

Fig. 11. Hydrograph analysis at the Rangendingen stream gauge station: estimated hydrograph based on recorded stages (reconstructed); peak flow estimated by post-event survey; model-based simulation.

June 2008 flood with the other floods may explain the relatively good results obtained by implementing the model on the five other floods.

Uncertainties in rainfall estimates and model simulations may affect the findings about the runoff ratio for the 2008 flood event. However, one should note that these values are in the range of those reported for specific small and medium size catchments and for events characterized by short rain durations in Continental Europe (Zoccatelli et al., 2010). When considering these events, it is apparent that the rainfall duration is an important control on runoff ratio, with initial losses accounting for an important contribution to the overall losses. Moreover, these results show that the runoff ratio exhibits a very limited variation to rainfall depth, particularly for short duration events.

The hydrological model was applied to simulate peak discharges over 17 sub-catchments where IPEC post-flood 
Table 3. Rainfall and runoff properties for the 2 June 2008 flood analysed at Rangendingen and at Jungingen (analysis based on the hydrological model application).

\begin{tabular}{lrrrrrr}
\hline Basin & $\begin{array}{r}\text { Area } \\
\left(\mathrm{km}^{2}\right)\end{array}$ & $\begin{array}{r}\text { Rain } \\
(\mathrm{mm})\end{array}$ & $\begin{array}{r}\text { Runoff } \\
(\mathrm{mm})\end{array}$ & $\begin{array}{r}\text { Peak } \\
\text { discharge } \\
\left(\mathrm{m}^{3} \mathrm{~s}^{-1}\right)\end{array}$ & $\begin{array}{r}\text { Unit peak } \\
\text { discharge } \\
\left(\mathrm{m}^{3} \mathrm{~s}^{-1} \mathrm{~km}^{-2}\right)\end{array}$ & $\begin{array}{r}\text { Runoff } \\
\text { ratio }\end{array}$ \\
\hline Rangendingen & 120.0 & 85.6 & 10.9 & 146.0 & 1.21 & 0.13 \\
Jungingen & 33.2 & 87.8 & 14.4 & 60.0 & 1.81 & 0.16 \\
\hline
\end{tabular}

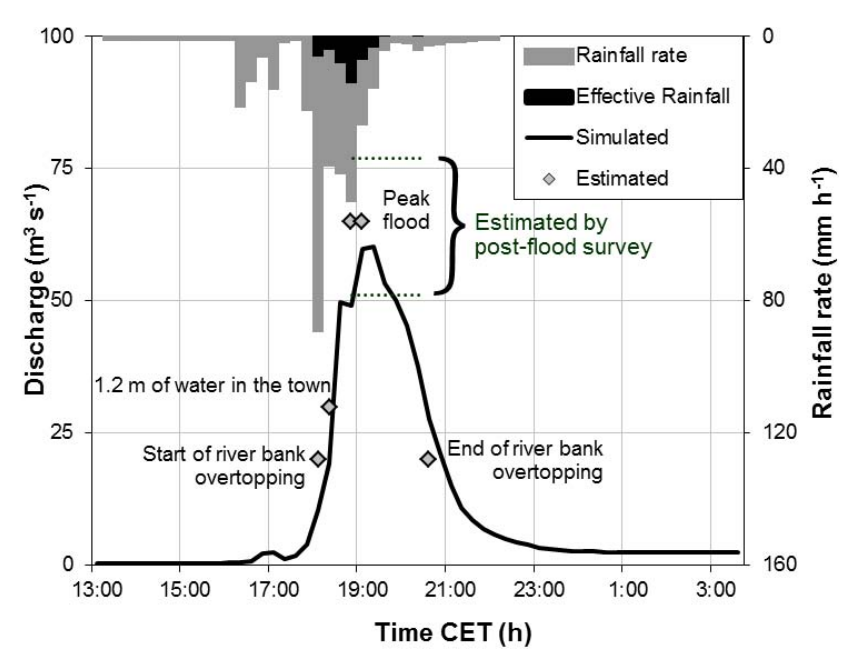

Fig. 12. Flood hydrograph simulation in Jungingen. The diamonds indicate the reported timing of flooding features from eyewitnesses.

surveys are available. Corresponding results are provided in Fig. 13a, b for the peak discharges and the unit peak discharges, respectively. In both figures, the uncertainty ranges for field-derived peak discharges are shown together with the central values. The results reported in Fig. 13a show a good fit between simulated and observed peak discharges, with a Nash-Sutcliffe efficiency equal to 0.91. Overall, this suggests that the hydrological model provides a reasonably good description of the spatial distribution of the runoff response to the extreme rain, at least for catchments exceeding a threshold area of around $10 \mathrm{~km}^{2}$. The success in the hydrological simulation may be ascribed to the strong forcing of the rainfall, which was estimated with relatively good accuracy for the study basin and was likely able to overcome other sources of spatial variability (such as those related to soil/geological properties) which are more difficult to determine. When considering these results, one should take into account that this representation tends to weight more the large discharges. Analysis of the results obtained for the unit peak discharges (Fig. 13b) permits closer examination of the simulations for the smaller basins. The examination allows one to isolate the behavior of the tributaries corresponding to Sites 37, 12 and 26, all corresponding to very small catchments (Table 1), where simulated peak values are substan- tially lower than the very high specific values obtained by the IPEC. For Site 25, the simulated value exceeds significantly the field-derived peak discharge. Several sources of uncertainties may be considered to explain the difficulties in reproducing the flood for these small basins. These sources of uncertainty certainly include possible errors in rainfall estimation, as well as difficulties in delineating the actual extension of the catchments and errors in indirect peak discharge estimation.

Model simulated peak values were also contrasted with the uncertainty range of the field-derived peak discharges to examine their hydrologic consistency. With this analysis, the surveyed catchments for which the uncertainty range of the field-derived peak discharges doesn't include the simulated peak discharges were screened out, as the error between field-based and model-based peak discharges was considered to be excessive. Nine sites were flagged as inconsistent. The majority of these catchments have size less than $10 \mathrm{~km}^{2}$, indicating that uncertainty in flood estimation is mainly concentrated at this range of basin size. This is due to various sources of uncertainty which include rainfall estimation, structural and parameter uncertainty in the hydrological model and potential errors in indirect peak flow estimation.

Values of runoff ratios were computed for the eight IPEC catchments considered as 'consistent' in the previous step. The relationship between the event runoff ratio and the corresponding rainfall depth is reported in Fig. 14. These values embrace well the value of runoff ratio computed for Rangendingen and Jungingen, with values ranging from 0.08 to 0.18 . Overall, these values support the finding concerning the low value of runoff ratio for the concerned flood event. Land use (Fig. 14) may explain the relatively high runoff ratio for Site 32, which is the one characterized by the largest contribution of urban land use among those investigated here.

\subsection{Influence of storm motion on modelled hydrograph properties}

To investigate the effect of rainfall space-time variability and storm motion on modelled hydrograph properties, we carried out a series of hydrologic simulations for which rainfall scenarios with different levels of rainfall variability and storm velocity were used. More specifically, the hydrologic response resulting from the original rainfall field (control simulation) was compared with the results obtained from 

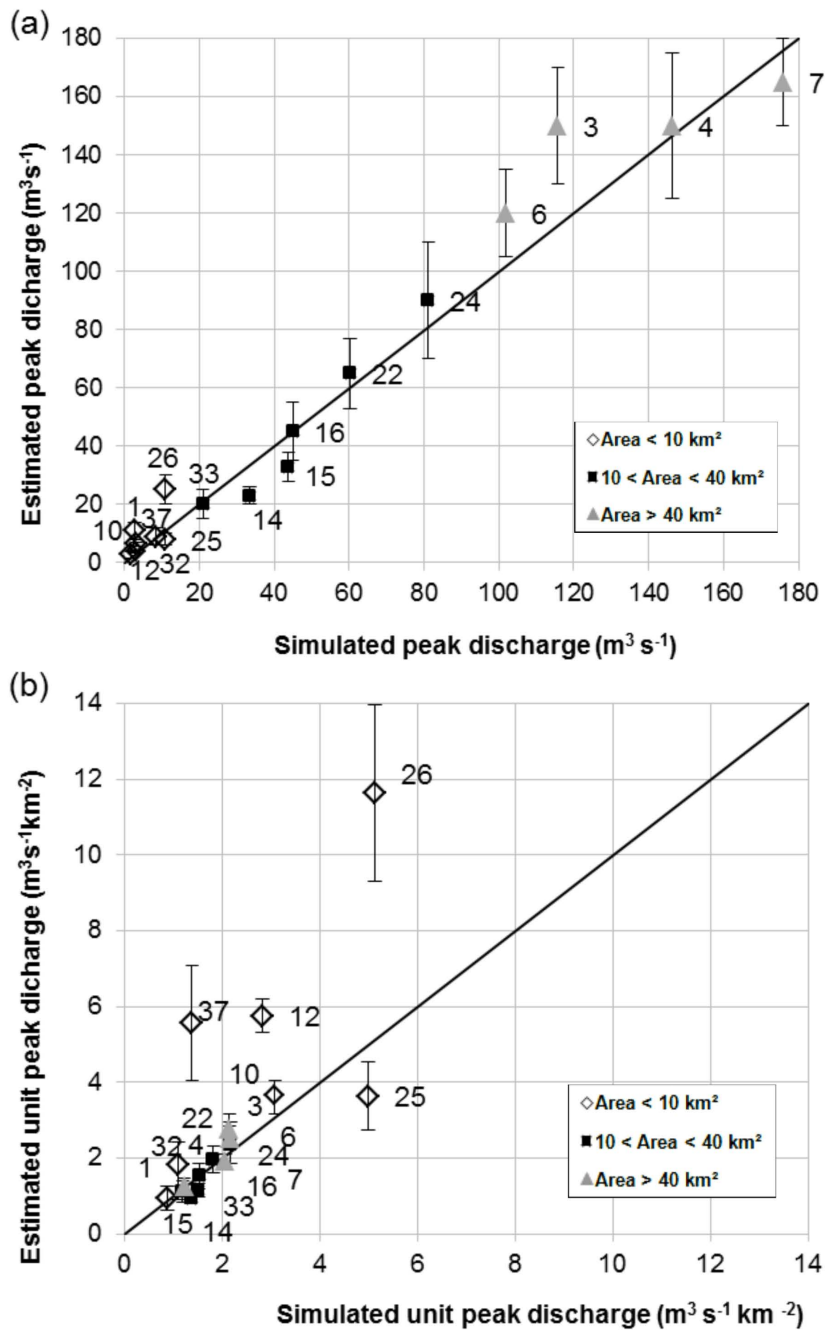

Fig. 13. Result from runoff model applications over the 17 IPEC catchments, by considering uncertainty ranges in indirect peak discharge estimation: (a) estimated versus simulated peak discharges; (b) estimated versus simulated unit peak discharges. Nash Sutcliffe efficiency statistics are 0.92 and 0.45 , respectively.

(a) spatially uniform and (b) constant spatial rainfall pattern case. In all cases the basin-averaged rainfall remained constant (i.e. constant rainfall volume applied at each time) while the spatial rainfall pattern was (a) completely removed (in the uniform case) or (b) kept constant and equal to the total rainfall accumulation pattern (constant pattern case). The latter was achieved by scaling the total rainfall pattern with an appropriate factor so that the basin-averaged rainfall remained equal to the original rain. Note that because the overall spatial rainfall organization is preserved in the constant pattern case, the values of $\Delta_{1}$ are the same as in the control scenario.

The rationale for developing the three rainfall scenarios is as follows. In our methodology, based on spatial moments, we assume that the shape of the flood hydrograph is controlled by: (i) the catchment drainage struc-

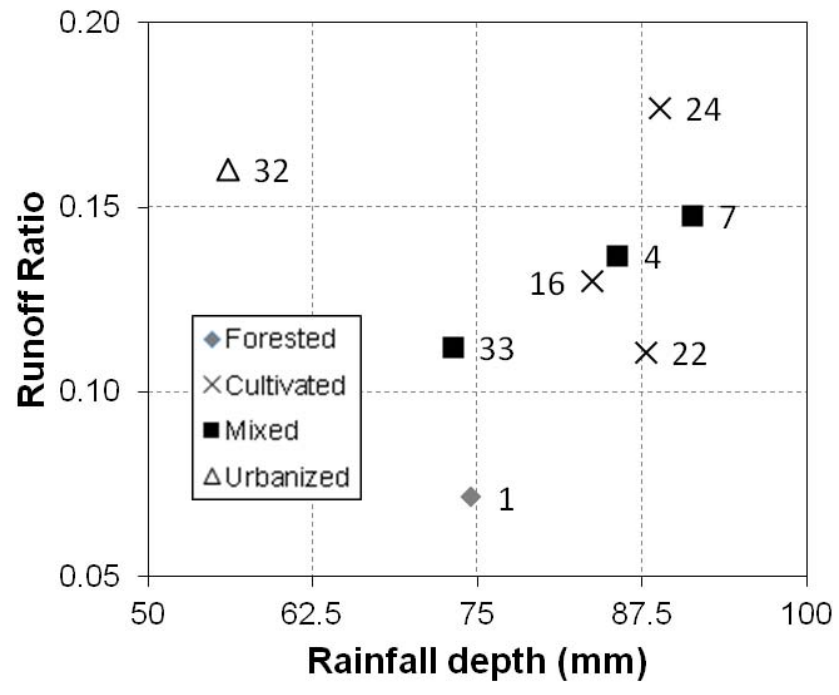

Fig. 14. Relationship between runoff ratio and rainfall depth for 8 IPEC catchments showing consistency between surveyed and simulated peak discharges.

ture, (ii) the temporal pattern of basin-average rainfall rates (hyetograph); (iii) the spatial distribution of rainfall within the basin and characterized by the spatial moments, and (iv) the storm dynamics characterized by the catchment scale storm velocity. The control simulation is the result of the combination of factors (i) to (iv), the constant pattern simulation is controlled by factors (i) to (iii), whereas the uniform-rainfall simulation is controlled by factors (i) and (ii). Comparison of control simulation with constant pattern simulation permits isolation of the effect of catchment scale storm velocity on flood hydrograph, whereas the comparison of control simulation with uniform-rainfall simulation isolates the combined effect of $\Delta_{1}$ and catchment scale storm velocity on flood hydrograph.

Simulations were carried out for the basin closed at Rangendingen (Fig. 15). Examination of the figure shows that the simulated peak flow increases from uniform rainfall $\left(107 \mathrm{~m}^{3} \mathrm{~s}^{-1}\right)$ to constant pattern $\left(127 \mathrm{~m}^{3} \mathrm{~s}^{-1}\right)$ to control scenario $\left(145 \mathrm{~m}^{3} \mathrm{~s}^{-1}\right)$. This clearly indicates that storm motion is an essential element of space-time rainfall, which plays a role in controlling hydrograph shape. Neglecting storm motion, by preserving only the shape of the spatial rainfall pattern, leads to underestimating the peak flow by $13 \%$. The underestimation rises to $26 \%$ assuming a spatially uniform rainfall distribution. These results are consistent with the discussion of Fig. 7 (sign of the peak flow underestimation and hydrograph amplitude agrees). Overall, this shows that the storm velocity played a non-negligible role in shaping the flood hydrograph during this event. It was the combination of the spatial distribution of rainfall field over the basin and its motion that controlled the flood response. 


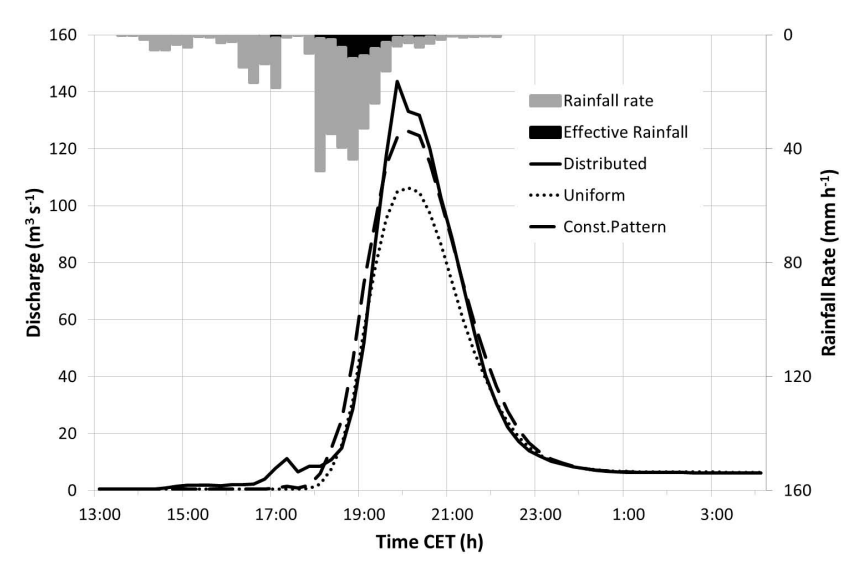

Fig. 15. Hydrograph analysis at the Rangendingen stream gauge station: resulting model-based hydrographs by using control rainfall (Distributed), spatially uniform rainfall (Uniform) and constant spatial pattern (Const. Pattern).

\section{Discussion and conclusions}

In this study we have examined the 2 June 2008 extreme flash floods on the Starzel river basin in South-West Germany. The major findings of this work are:

- The Hilal organised system of thunderstorms produced record rainfall and flooding in the Starzel river basin at basin scales ranging from 1 to $120 \mathrm{~km}^{2}$. The magnitude of the flooding in terms of rainfall rates and unit peak discharge was comparable to that observed in the same region for past extreme events and for other central European storms producing extreme flooding at these scales. The Hilal event provides a prototype for organized convective systems that dominate the upper tail of the precipitation frequency distribution in the study region as well as in several other contexts in Central Europe.

- The combined approach of hydrological modeling based on rainfall observations and indirect peak discharge estimates based on field survey offers the opportunity to compare peak flow estimates from independent approaches. This greatly helps to validate the results of flood reconstruction and to estimate related uncertainty bounds. This analysis has shown that uncertainty in flood simulation is mainly concentrated at scales less than $10 \mathrm{~km}^{2}$, due to various sources of uncertainty which include rainfall estimation, structural and parameter uncertainty in the hydrological model and potential errors in indirect peak flow estimation.

- Even though the antecedent soil moisture conditions were relatively wet, small runoff ratios (less than $20 \%$ ) characterized the runoff response at Rangendingen. Uncertainties in rainfall estimates and model simulations may affect these results. Anyway, it is shown that these values are in the range of values of runoff ratios computed for other less extreme floods recorded at Rangendingen. Also, the values reported for Rangendingen are in the range of those computed for other 8 surveyed catchments. Overall, this support the view that runoff ratio estimates obtained in this work are robust and may provide an indication for runoff generation triggered by short and intense rainfall in small to medium rural catchments in Central Europe (Zoccatelli et al., 2010).

- The distributed flood response can be reasonably well reproduced with a simple distributed hydrological model, using high resolution rainfall observations and model parameters calibrated at a river section which includes most of the area impacted by the storm. The model is capable of consistently reproducing the flood peaks at 8 sites (out of 17) estimated during the intensive post-flood survey. To examine the performance of the model in simulating different floods, the model was applied to five moderate flood events selected in the period 2002 to 2010. The model results shows that parameters identified on an extreme event may be transported to less extreme cases, when initial conditions are properly accounted for. It remains to be shown if the inverse, more useful, process of parameters identification on moderate events for use in extreme flood cases may be also successful. Similarly, further efforts should be directed to examine how these results can be extended to other cases.

- The Hilal organized system of thunderstorms was characterized by its rapid storm motion. We developed a methodology that affords isolation of the effects of storm motion on flood response. The rapid downbasin motion of the principal rain band was important, even though not dominant, in controlling the magnitude of the runoff response, by increasing the modeled flood peak by $13 \%$. This suggests that fine space and time rainfall resolution is required to effectively monitor the storm characteristics which may be important for flood forecasting in the study region.

Acknowledgements. This work was financially supported by the EU FP6 STREP Project HYDRATE, Contract GOCE-037024. The post-flood survey was carried out in collaboration with the authorities of Regierungspräsidium Stuttgart, Tübingen and Freiburg as well as the local municipalities of Jungingen and Hechingen. The first author acknowledges the Spanish Ministry of Science and Innovation, for the grant for a 4 months research stay at the University of Padova (Italy), MAS Dendro-Avenidas project (CGL2010-19274) and the Geological Survey of Spain and University of Castilla-La Mancha, particularly to Andrés Díez-Herrero and Jose M. Bodoque for their support and collaboration.

Edited by: R. Uijlenhoet 


\section{References}

Beven, K. and Wood, E.: Catchment and geomorphology and the dynamics of the runoff contributing areas, J. Hydrol., 65, 139$158,1983$.

Blöschl, G.: Hydrologic synthesis: Across processes, places, and scales, Water Resour. Res., 42, W03S02, doi:10.1029/2005WR004319, 2006.

Borga, M., Boscolo, P., Zanon, F., and Sangati, M.: Hydrometeorological analysis of the August 29, 2003 flash flood in the eastern Italian Alps, J. Hydromet., 8, 1049-1067, 2007.

Borga, M., Gaume, E., Creutin, J. D., and Marchi, L.: Surveying flash flood response: gauging the ungauged extremes, Hydrol. Processes, 22, 3883-3885, doi:10.1002/hyp.7111, 2008.

Borga, M., Anagnostou, E. N., Blöschl, G., and Creutin, J. D.: Flash flood forecasting, warning and risk management: the HYDRATE project, Environ. Sci. Policy, 14, 834-844, 2011.

Bonnifait, L., Delrieu, G., Lay, M. L., Boudevillain, B., Masson, A., Belleudy, P., Gaume, E., and Saulnier, G.-M.: Distributed hydrologic and hydraulic modelling with radar rainfall input: Reconstruction of the 8-9 September 2002 catastrophic flood event in the Gard region, France, Adv. Water Resour., 32, 1077-1089, 2009.

Botter, G. and Rinaldo, A.: Scale effect on geomorphologic and kinematic dispersion, Water Resour. Res., 39, 1286, doi:10.1029/2003WR002154, 2003.

Bouilloud, L., Delrieu, G., Boudevillain, B., Borga, M., and Zanon, F.: Radar rainfall estimation for the post-event analysis of a Slovenian flash-flood case: application of the Mountain Reference Technique at C-band frequency, Hydrol. Earth Syst. Sci., 13, 1349-1360, doi:10.5194/hess-13-1349-2009, 2009.

Braud, I., Roux, H., Anquetin, S., Maubourguet, M. M., Manus, C., Viallet, P., and Dartus, D.: The use of distributed hydrological models for the Gard 2002 flash flood event: Analysis of associated hydrological processes, J. Hydrol., 394, 162-181, doi:10.1016/j.jhydrol.2010.03.033, 2010.

Brauer, C. C., Teuling, A. J., Overeem, A., van der Velde, Y., Hazenberg, P., Warmerdam, P. M. M., and Uijlenhoet, R.: Anatomy of extraordinary rainfall and flash flood in a Dutch lowland catchment, Hydrol. Earth Syst. Sci., 15, 1991-2005, doi:10.5194/hess15-1991-2011, 2011.

Carpenter, T. M., Wang, J., Taylor, S. V., Shamir, E., Sperfslage, J. A., and Georgakakos, K. P.: Surveying flash flood response in mountain streams, Eos, 88, 69-72, doi:10.1029/2007EO060001, 2007.

Costa, J. E. and Jarrett, R. D.: An evaluation of selected extraordinary floods in the United States Reported by the US Geological Survey and implications for future advancement of flood science, US Geological Survey, Scientific Investigations Report 20085164, 52 pp., 2008.

Delrieu, G., Caoudal, S., and Creutin, J. D.: Feasibility of using mountain return for the correction of ground-based X-band weather radar data, J. Atmos. Ocean. Technol., 14, 368-385, 1997.

Delrieu, G., Nicol, J., Yates, E., Kirstetter, P-E., Creutin, J.-D., Anquetin, S., Obled, Ch., Saulnier, G.-M., Ducrocq, V., Gaume, E., Payrastre, O., Andrieu, H., Ayral, P.-A., Bouvier, C., Neppel, L., Livet, M., Lang, M., Parentdu-Châtelet, J., Walpersdorf, A., and Wobrock, W.: The Catastrophic Flash-Flood Event of 8-9 September 2002 in the Gard Region, France: A First Case Study for the Cévennes-Vivarais Mediterranean Hydrometeorological Observatory, J. Hydrometeorol., 6, 34-52, 2005.

Dunne, T.: Field studies in hillslope flow processes, in Hillslope Hydrology, edited by: Kirkby, M. J., 227-294, John Wiley, Hoboken, N. J., 1978.

DWD: Deutscher Wetterdienst: Starkniederschlagshöhen für die Bundesrepublik Deutschland - KOSTRA, Offenbach am Main, Eigenverlag des Deutschen Wetterdienstes, 1997.

DWD: Deutscher Wetterdienst: KOSTRA-DWD-2000. Starkniederschlagshöhen für die Bundesrepublik Deutschland (1951-2000) - Fortschreibungsbericht, Offenbach am Main, Eigenverlag des Deutschen Wetterdienstes, 2006.

Gaume, E. and Borga, M.: Post flood field investigations after major flash floods: proposal of a methodology and illustrations, Journal of Flood Risk Management, 1, 175-189, doi:10.1111/j.1753318X.2008.00023.x, 2008.

Gaume, E., Bain, V., Bernardara, P., Newinger, O., Barbuc, M., Bateman, A., Blaškovièová, L., Blöschl, G., Borga, M., Dumitrescu, A., Daliakopoulos, I., Garcia, J., Irimescu, V., Kohnova, S., Koutroulis, A., Marchi, L., Matreata, S., Medina, V., Preciso, E., Sempere-Torres, D., Stancalie, G., Szolgay, J., Tsanis, I., Velasco, D., and Viglione, A.: A collation of data on European flash floods, J. Hydrol., 367, 70-78, doi:10.1016/j.jhydrol.2008.12.028, 2009.

Gaume, E., Gaál, L., Viglione, A., Szolgay, J., Kohnová, S., and Blöschl, G.: Bayesian MCMC approach to regional flood frequency analyses involving extraordinary flood events at ungauged sites, J. Hydrol., 394, 101-117, doi:10.1016/j.jhydrol.2010.01.008, 2010.

Hicks, N. S., Smith, J. A., Miller, A. J., and Nelson, P. A.: Catastrophic flooding from an orographic thunderstorm in the central Appalachians, Water Resour. Res., 41, W12428, doi:10.1029/2005WR004129, 2005.

Lumbroso, D. and Gaume, E.: Reducing the uncertainty in indirect estimates of extreme flash flood discharges, J. Hydrol., 414-415, 16-30, 2012.

Marchi, L., Borga, M., Preciso, E., Sangati, M., Gaume, E., Bain, V., Delrieu, G., Bonnifait, L., and Poganèik, N.: Comprehensive post-event survey of a flash flood in Western Slovenia: observation strategy and lessons learned, Hydrol. Process., 23, 37613770, doi:10.1002/hyp.7542, 2009.

Marchi, L., Borga, M., Preciso, E., and Gaume, E.: Characterisation of selected extreme flash floods in Europe and implications for flood risk management, J. Hydrol., 394, 118-133, doi:10.1016/j.jhydrol.2010.07.017, 2010.

Norbiato, D., Borga, M., Degli Esposti, S., Gaume, E., and Anquetin, S.: Flash flood warning based on rainfall thresholds and soil moisture conditions: An assessment for gauged and ungauged basins, J. Hydrol., 362, 274-290, 2008.

Ogden, F. L. and Saghafian, B.: Green and Ampt infiltration with redistribution, J. Irrig. Drain. E.-ASCE, 123, 386-393, 1997.

Ogden, F. L., Richardson, J. R., and Julien, P. Y.: Similarity in catchment response: 2. Moving rainstorms, Water Resour. Res., 31, 1543-1547, 1995.

Parajka, J., Kohnová, S., Bálint, G., Barbuc, M., Borga, M., Claps, P., Cheval, S., Gaume, E., Hlavèová, K., Merz, R., Pfaundler, M., Stancalie, G., Szolgay, J., and Blöschl, G.: Seasonal characteristics of flood regimes across the Alpine-Carpathian range, J. Hydrol., 394, 78-89, doi:10.1016/j.jhydrol.2010.05.015, 2010. 
Pilgrim, D. H.: Travel times and nonlinearity of flood runoff from tracer measurements on a small watershed, Water. Resour. Res., 12, 487-496, 1976.

Seo, Y., Schmidt, A. R. and Sivapalan, M.: Effect of storm movement on flood peaks: Analysis framework based on characteristic timescales, Water Resour. Res., 48, W05532, doi:10.1029/2011WR011761, 2012.

Serrar, S., Delrieu, G., Creutin, J. D., and Uijlenhoet, R.: Mountain reference technique: Use of mountain returns to calibrate weather radars operating at attenuating wavelengths, J. Geophys. Res.Atmos., 105, 2281-2290, 2000.

Singh, V. P.: Effect of the direction of storm movement on planar flow, Hydrol. Process., 12, 147-170, 1998.

Smith, J. A., Baeck, M. L., Morrison, J. E., Sturdevant-Rees, P. L., Turner-Gillespie, D. F., and Bates, P. D.: The regional hydrology of extreme floods in an urbanizing drainage basin, J. Hydrometeorol., 3, 267-282, 2002.

Smith, J. A., Baeck, M. L., Meierdiercks, K. L., Nelson, P. A., Miller, A. J., and Holland, E. J.: Field studies of the storm event hydrologic response in an urbanizing watershed, Water Resour. Res., 41, W10413, doi:10.1029/2004WR003712, 2005.
Uhlenbrook, S., Steinbrich, A., Tetzlaff, D., and Leibundgut, C.: Regional analysis of the generation of extreme floods, IAHS-AISH Publication, 274, 243-249, 2002.

Versini, P.-A., Gaume, E., and Andrieu, H.: Application of a distributed hydrological model to the design of a road inundation warning system for flash flood prone areas, Nat. Hazards Earth Syst. Sci., 10, 805-817, doi:10.5194/nhess-10-805-2010, 2010.

Viglione, A., Chirico, G. B., Woods, R., and Blöschl, G.: Generalised synthesis of space-time variability in flood response: An analytical framework, J. Hydrol., 394, 198-212, doi:10.1016/j.jhydrol.2010.05.047, 2010.

Zanon, F., Borga, M., Zoccatelli, D., Marchi, L., Gaume, E., Bonnifait, L., and Delrieu, G.: Hydrological analysis of a flash flood across a climatic and geologic gradient: the September 18, 2007 event in Western Slovenia, J. Hydrol., 394, 182-197, doi:10.1016/j.jhydrol.2010.08.020, 2010.

Zoccatelli, D., Borga, M., Viglione, A., Chirico, G. B., and Blöschl, G.: Spatial moments of catchment rainfall: rainfall spatial organisation, basin morphology, and flood response, Hydrol. Earth Syst. Sci., 15, 3767-3783, doi:10.5194/hess-15-37672011, 2011. 